The Free Internet Journal

for Organic Chemistry
Paper

Arkivoc 2017, part v, 301-313

Organic Chemistry

\title{
Stereoselective synthesis of fully functionalized acyclic core of Tianchimycin A
}

\author{
Vanipenta Yamini and Subhash Ghosh* \\ Organic and Biomolecular Chemistry Division, CSIR-Indian Institute of Chemical Technology, Uppal Road, \\ Tarnaka, Hyderabad 500007, India \\ E-mail: subhash@iict.res.in
}

Received 07-31-2017

Accepted 10-18-2017

Published on line 11-19-2017

\section{Abstract}

A highly convergent synthetic approach towards the macrolactone polyketide tianchimycin A is described. Notable features of our synthetic approach include highly stereoselective Myers alkylation, substrate controlled anti aldol reaction, and Masamune-Roush olefination.

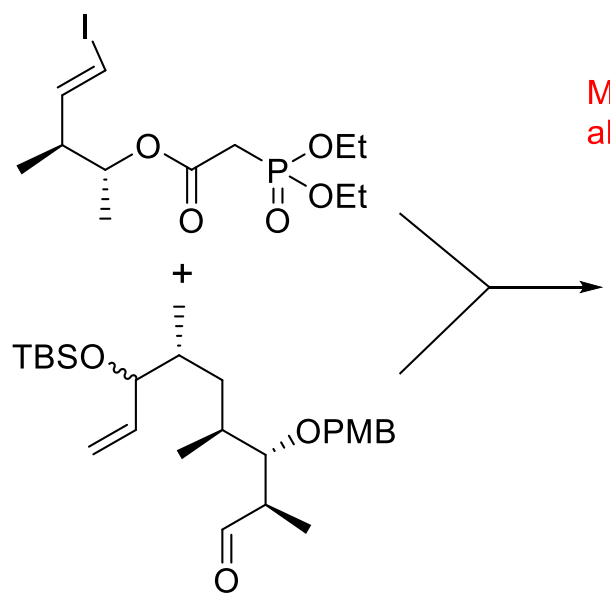

Myers asymmetric

alkylation Crimmin's

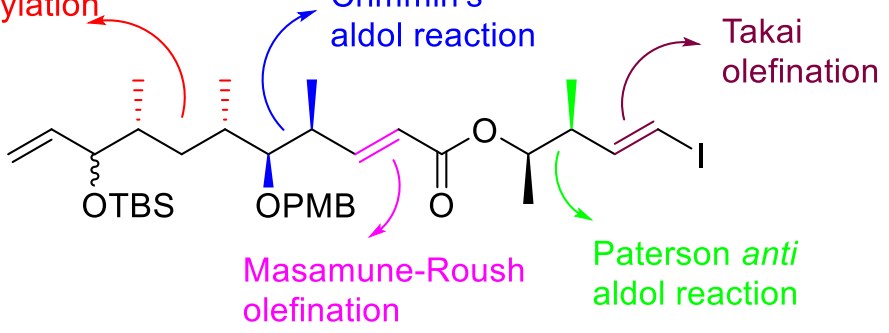

Acyclic core of tianchimycin A

Keywords: Tianchimycin, Crimmins's protocol, Paterson's aldol reaction, Takai olefination, Masamune-Roush olefination, intramolecular Heck-cyclization 


\section{Introduction}

Actinobacteria are important sources of bioactive secondary metabolites. ${ }^{1}$ In 2013 , Deng and co-workers isolated two new 16-membered macrolactone type polyketides from the rare actinomycete Saccharothrix xinjiangensis B-24321 and named them as tianchimycin A and tianchimycin B (Figure 1). ${ }^{2}$ Structures of tianchimycins A-B were determined based on detailed NMR and MS spectroscopy. Architecturally tianchimycin $A$ is quite interesting. It is a macrocyclic lactone adorned with six stereogenic centers and three olefinic moieties. Out of three double bonds, two are part of 1,4-butadiene system and the third one is a part of $\alpha, \beta$ unsaturated lactone moiety. Initial biological studies revealed that they do not have antibacterial activity. However modification of the structure might provide good antibacterial lead. Thus with this intention we initiated a program for the total synthesis of tianchimycin $A$ and its analogs to unveil the full biological potential. In 2015 Sabitha et al. reported the synthetic study of tianchimycin A. They synthesized the entire acyclic C1-C16 framework of the molecule. However the macrolactonization under different conditions was unsuccessful. ${ }^{3}$ Thus we thought an alternate approach to construct 1 could be intramolecular Heck-cyclization for the formation of macrocyclic ring. ${ }^{4}$ Recently the employment of intramolecular Heck reaction for macrocyclization has flourished in natural product synthesis. ${ }^{4,16,17,18,19} \mathrm{It}$ is interesting to note that this reaction is applicable to variation depending upon the macrocyclic ring size (16-24 size macrocycles), which requires optimization of variety of reaction parameters.

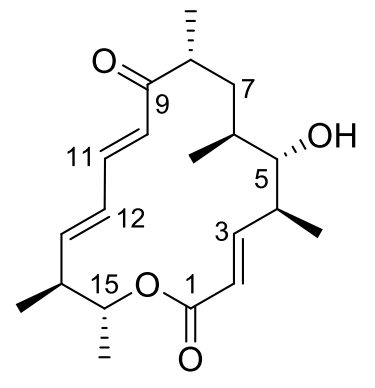

Tianchimycin A (1)

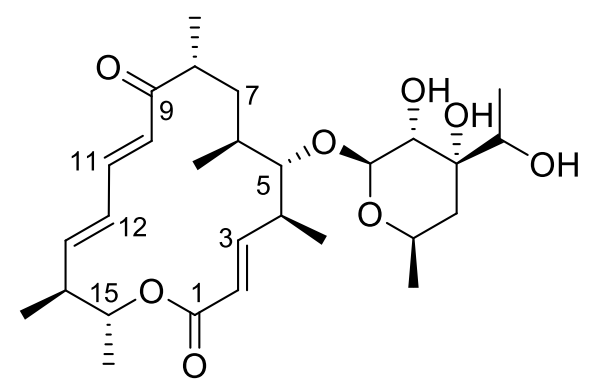

Tianchimycin B (2)

Figure 1. Structures of Tianchimycins.

\section{Results and Discussion}

Retrosynthetically, we dissected $\mathbf{3}$ into building blocks $\mathbf{4}$ and $\mathbf{5}$ (Scheme 1). Heck coupling of substrate $\mathbf{3}$ was envisaged as a key step to close the macrocycle, while connection of the cyclization precursor $\mathbf{3}$ was planned to arise from Masamune-Roush olefination of aldehyde 4 and ketophosphonate 5. 5,6 The aldehyde 4 would be acquired from the known compound $\mathbf{7}^{7}$ using Myers asymmetric alkylation and the ketophosphonate $\mathbf{5}$ might be synthesized from known compound $\mathbf{9}^{8}$ using Paterson's anti aldol reaction. 

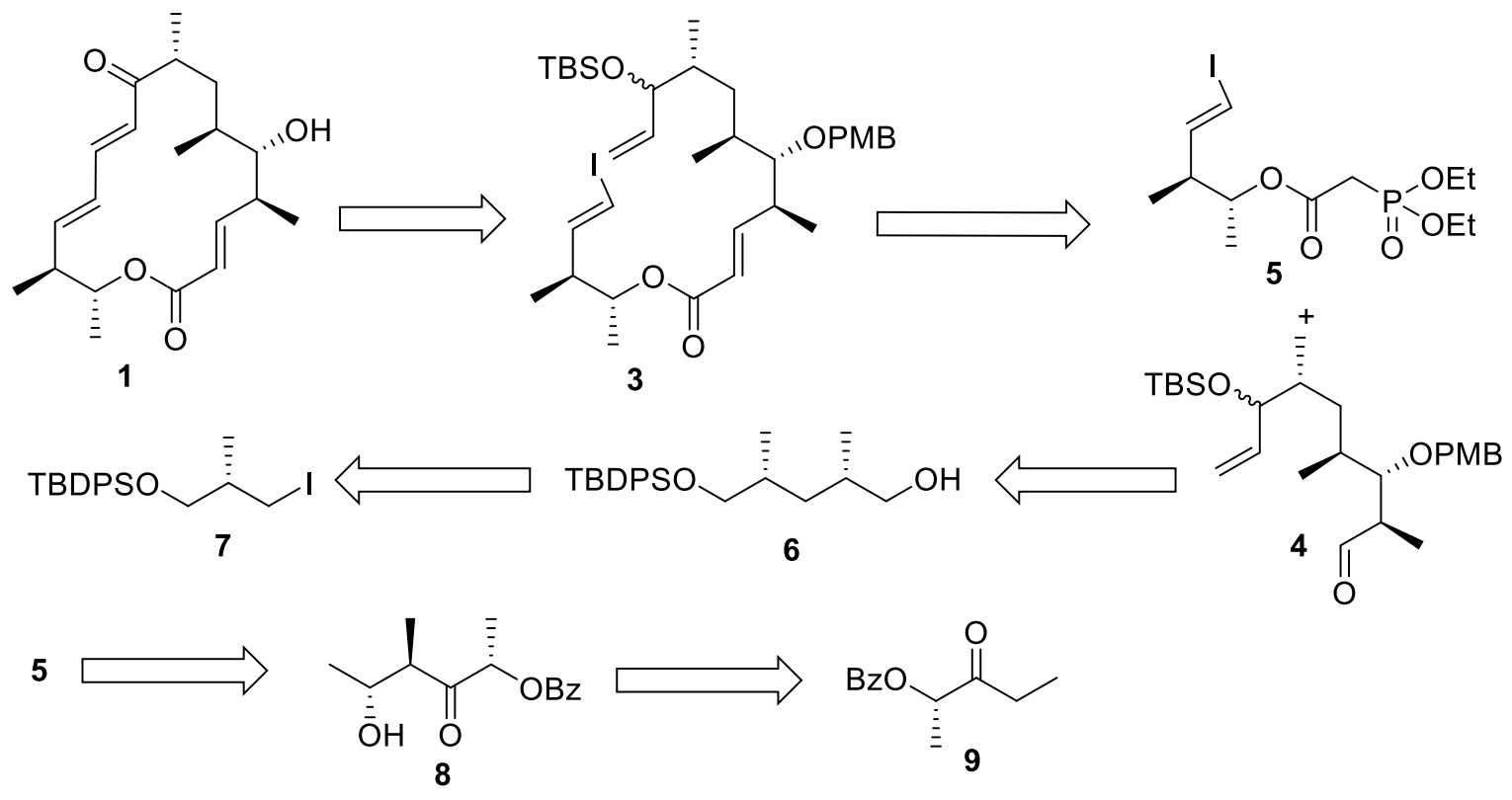

Scheme 1. Retrosynthetic analysis of tianchimycin A.

From the synthetic perspective, synthesis of $\mathbf{4}$ (Scheme 2) began with the diastereoselective alkylation of the known iodide $\mathbf{7}^{7}$ with Myers pseudoephedrine derived auxiliary.10 to yield amide $\mathbf{1 0}$ as a single diastereomer in 95\% yield. Reduction of 10 with $\mathrm{BH}_{3} . \mathrm{NH}_{3}$ gave primary alcohol 6 in $90 \%$ yield. Compound 6 on oxidation under Dess-Martin Periodinane conditions provided an aldehyde, to which addition of (Z)-enolate, generated from 11, using Crimmins's protocol ${ }^{11}$ afforded 12 with excellent diastereoselectivity (98:2 dr), which are separated by standard silica gel column chromatography to obtain the required single isomer 12 in $96 \%$ yield. Reductive removal of the chiral auxiliary with $\mathrm{LiBH}_{4}$ in ether furnished the 1,3-diol compound 13, which on protection as PMP-acetal followed by TBDPS deprotection with TBAF gave a primary alcohol 15. Oxidation of 15 with DMP gave an aldehyde which on reaction with vinylmganesium bromide yielded diastereomerically mixture of alcohols 16, which on TBS protection with TBSOTf in presence of 2,6-lutidine gave globally protected compound 17. At this stage the $p$-methoxybenzylidine acetal of $\mathbf{1 7}$ was opened regioselectively with DIBAL-H to give a primary alcohol $\mathbf{4 a}$, which was oxidized with DMP to give required aldehyde $\mathbf{4}$ in $90 \%$ yield. 


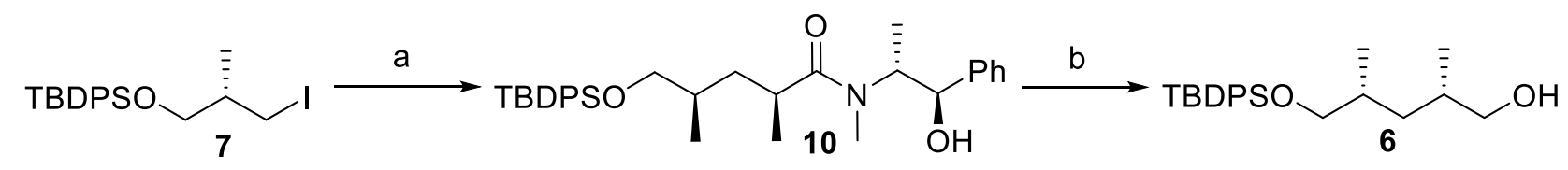

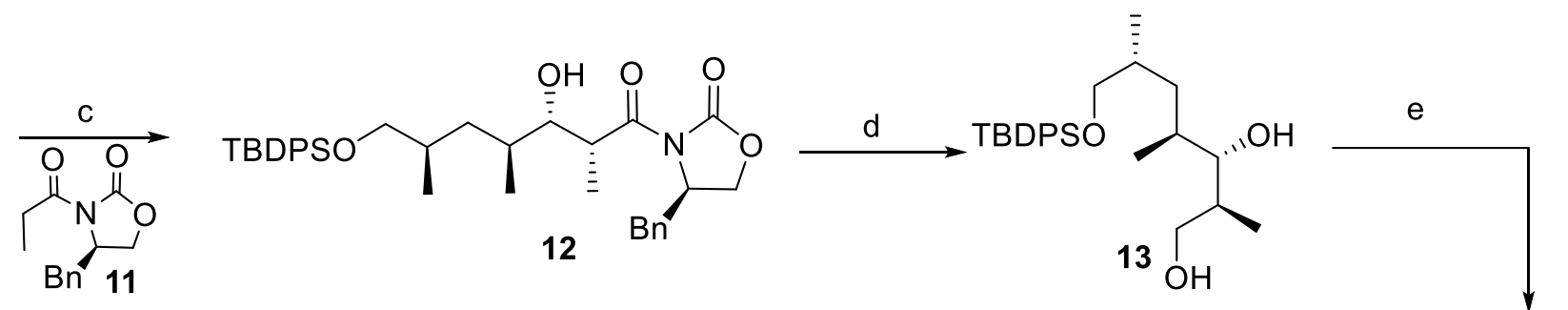

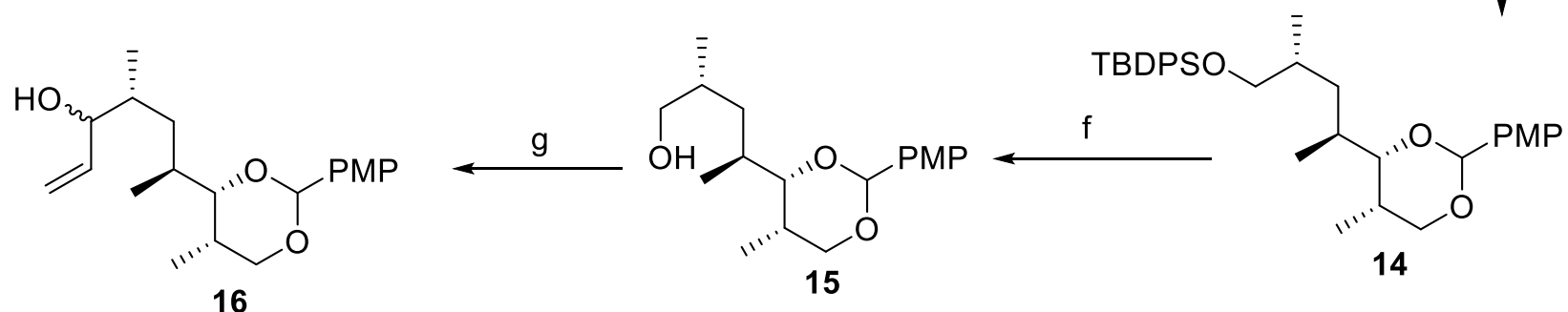<smiles>[Y16]C1OC[C@@H](C)[C@@H]([C@H](C)C[C@H](C)[C@H](C=C)OC(C)(C)C)O1</smiles><smiles>[R16]O[C@@H](C([R])C)[C@@H](C)C[C@@H](C)[C@H](C=C)O[AsH3]</smiles>

$\begin{aligned} \text { j } C \text { a: } \mathrm{R} & =\mathrm{CH}_{2} \mathrm{OH} \\ 4: \mathrm{R} & =\mathrm{CHO}\end{aligned}$

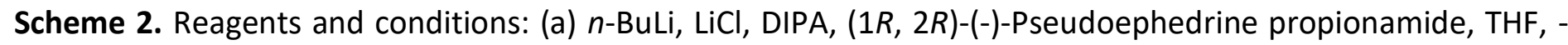
$78{ }^{\circ} \mathrm{C}--20{ }^{\circ} \mathrm{C}, 14 \mathrm{~h}, 95 \%$; (b) $n$-BuLi, LiCl, $\mathrm{BH}_{3} . \mathrm{NH}_{3}, \mathrm{THF}, 0{ }^{\circ} \mathrm{C}-\mathrm{rt}, 4 \mathrm{~h}, 90 \%$; (c) i. DMP, $\mathrm{NaHCO}_{3}, \mathrm{CH}_{2} \mathrm{Cl}_{2}, 0^{\circ} \mathrm{C}-\mathrm{rt}, 2$ h; ii. $\mathrm{TiCl}_{4}$, (-)-sparteine, $0{ }^{\circ} \mathrm{C}, \mathrm{CH}_{2} \mathrm{Cl}_{2}, 20 \mathrm{~min}$ then $11,0{ }^{\circ} \mathrm{C}, 10 \mathrm{~min}, 96 \%$ (over two steps); (d) $\mathrm{LiBH}_{4}, 0{ }^{\circ} \mathrm{C}, \mathrm{Et}_{2} \mathrm{O}$, 10 min, 96\%; (e) PMP-acetal, CSA (cat), $\mathrm{CH}_{2} \mathrm{Cl}_{2}, 0{ }^{\circ} \mathrm{C}$-rt, $12 \mathrm{~h}, 94 \%$; (f) TBAF, THF, $0{ }^{\circ} \mathrm{C}, 12 \mathrm{~h}, 91 \%$; (g) i. DMP, $\mathrm{NaHCO}_{3}, \mathrm{CH}_{2} \mathrm{Cl}_{2}, 0^{\circ} \mathrm{C}$-rt, $2 \mathrm{~h}$; ii. vinylmagnesium bromide, THF, $0{ }^{\circ} \mathrm{C}, 1 \mathrm{~h}, 84 \%$ (over two steps); (h) TBSOTf, 2,6lutidine, $\mathrm{CH}_{2} \mathrm{Cl}_{2}, 0{ }^{\circ} \mathrm{C}-\mathrm{rt}, 2 \mathrm{~h}, 93 \%$; (i) DIBAL-H, $\mathrm{CH}_{2} \mathrm{Cl}_{2},-40{ }^{\circ} \mathrm{C}-0{ }^{\circ} \mathrm{C}, 2 \mathrm{~h}, 90 \%$; (j) DMP, $\mathrm{NaHCO}_{3}, \mathrm{CH}_{2} \mathrm{Cl}_{2}, 0{ }^{\circ} \mathrm{C}-\mathrm{rt}, 2$ h.

Synthesis of phosphonate fragment 5 commenced from known keto compound $\mathbf{9}^{8}$ (Scheme 3 ), which on reaction with acetaldehyde under Paterson's anti-aldol conditions ${ }^{12,13}$ using dicyclohexylborane chloride afforded 8 -keto alcohol 8 , in $96 \%$ yield with excellent diastereoselectivity which was protected as its TBS ether to give compound 18 in $92 \%$ yield. Reduction of the keto as well as benzoate group in 18 with $\mathrm{LiBH}_{4}$ afforded diastereomerically mixture of diols 19 in $92 \%$ yield. ${ }^{7}$ Oxidative cleavage of the diol with $\mathrm{NaIO}_{4}$ furnished an aldehyde, which on Takai olefination gave vinyl iodide 20 ( $E: Z$ ratio 19:1) in 80\% yield over two steps. ${ }^{14,15}$ TBS deprotection from compound 20 furnished a secondary alcohol, which on acylation with diethyl phosphonoacetic acid under EDCI/DMAP conditions afforded the phosphonate $\mathbf{5}$ in $85 \%$ yield. 
<smiles>CCC(=O)[C@@H](C)O[R6](=O)c1ccccc1</smiles>

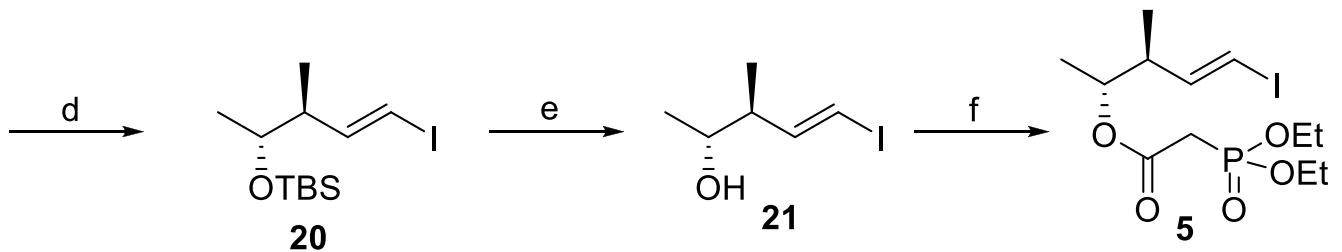

Scheme 3. Reagents and conditions: (a) $\mathrm{c}-\mathrm{Hex}_{2} \mathrm{BCl}, \mathrm{Me}_{2} \mathrm{NEt}$, acetaldehyde, $\mathrm{Et}_{2} \mathrm{O},-78{ }^{\circ} \mathrm{C}--20{ }^{\circ} \mathrm{C}, 14 \mathrm{~h}, 96 \%$; (b) TBSOTf, 2,6-lutidine, $\mathrm{CH}_{2} \mathrm{Cl}_{2}, 0^{\circ} \mathrm{C}-\mathrm{rt}, 2 \mathrm{~h}, 92 \%$; (c) $\mathrm{LiBH}_{4}, \mathrm{THF},-78{ }^{\circ} \mathrm{C}-0{ }^{\circ} \mathrm{C}, 21 \mathrm{~h}, 92 \%$; (d) i. $\mathrm{NaIO}_{4}, \mathrm{MeOH}^{-\mathrm{H}_{2} \mathrm{O}}$ (2:1), rt, 30 min; ii. $\mathrm{CHI}_{3}, \mathrm{CrCl}_{2}$, THF, rt, $1 \mathrm{~h}, 80 \%$ (over two steps); (e) TBAF, THF, $0{ }^{\circ} \mathrm{C}, 12 \mathrm{~h}, 91 \%$; (f) Diethyl phosphonoacetic acid, EDCl, DMAP, $\mathrm{CH}_{2} \mathrm{Cl}_{2}, 0{ }^{\circ} \mathrm{C}-\mathrm{rt}, 4 \mathrm{~h}, 85 \%$.

Having both the fragments in our hand, the Horner-Wadsworth-Emmons reaction ${ }^{5}$ under MasamuneRoush conditions was carried out between aldehyde $\mathbf{4}$ and the phosphonate 5 in presence of DBU and LiCl in acetonitrile to give key acyclic precursor 3 (Scheme 4) for intramolecular Heck-cyclization. At this stage the crucial intramolecular Heck-cyclization under assorted conditions (Table 1) was not successful leaving the total synthesis still elusive. . $^{46,17,18,19}$

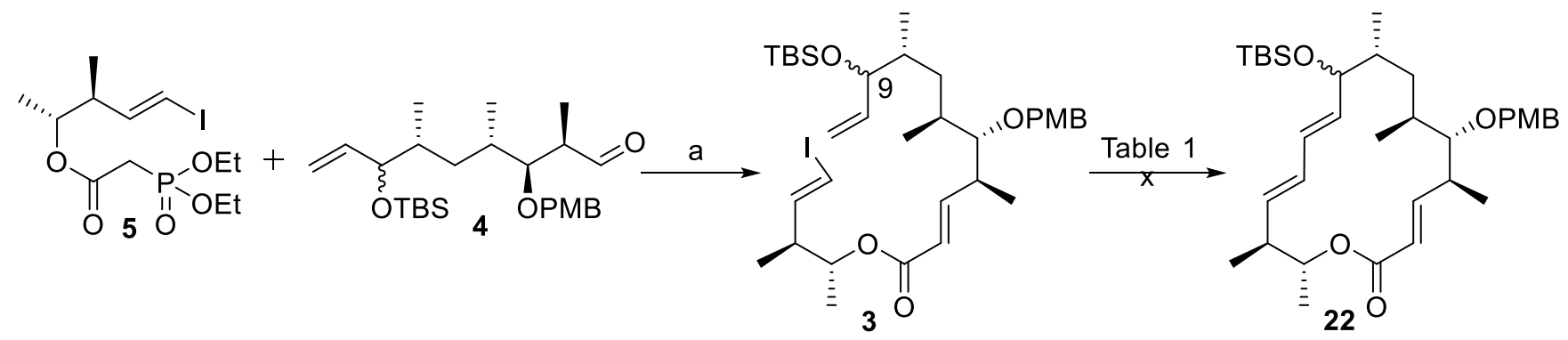

Scheme 4. Reagents and conditions: (a) $\mathrm{LiCl}, \mathrm{DBU}, \mathrm{CH}_{3} \mathrm{CN}, 0^{\circ} \mathrm{C}-\mathrm{rt}, 12 \mathrm{~h}, 77 \%$.

Table 1. Attempts to Intramolecular Heck cross Coupling for Macrocyclization.

\begin{tabular}{cccc}
\hline Sl. No & Catalyst & Conditions & Yield (\%) \\
\hline 1 & $\mathrm{Pd}(\mathrm{OAC})_{2}$ & $\mathrm{Cs}_{2} \mathrm{CO}_{3}, \mathrm{Et}{ }_{3} \mathrm{~N}, \mathrm{DMF}, \mathrm{rt}, 48 \mathrm{~h}$ & Decomposition \\
2 & $\mathrm{PdCl}(\mathrm{MeCN})_{2}$ & $\mathrm{Et}_{3} \mathrm{~N}, \mathrm{HCOOH}, \mathrm{MeCN}, \mathrm{rt}, 1 \mathrm{~h}$ & Decomposition \\
3 & $\mathrm{Pd}(\mathrm{OAc})_{2}$ & $\mathrm{~K}_{2} \mathrm{CO}_{3}, \mathrm{DMF}, 80^{\circ} \mathrm{C}, 24 \mathrm{~h}$ & Decomposition \\
4 & $\mathrm{Pd}(\mathrm{OAc})_{2}$ & $\mathrm{~K}_{2} \mathrm{CO}_{3}, \mathrm{Bu} 4 \mathrm{NCl}, \mathrm{DMF}, 60^{\circ} \mathrm{C}, 1 \mathrm{~h}$ & Decomposition \\
\hline
\end{tabular}

\section{Conclusions}

The synthesis of acyclic precursor of macrocyclic tianchimycin A was achieved by employing Myers asymmetric alkylation, Crimmins's aldol reaction, Paterson's aldol reaction, Takai olefination and Masamune-Roush olefination as key steps. Currently we are working to develop a diverse strategy to circumvent the problem of 
macrocyclization, which might help us to achieve the total synthesis of tianchimycin A and its potential analogs and for biological screening, which will be reported in due course.

\section{Experimental Section}

General. All the reactions were performed in oven-dried glass apparatus under nitrogen or argon atmosphere under magnetic stirring. Standard methods were used to make anhydrous solvents. Unless otherwise noted, commercially available reagents were used without further purification. Glass columns packed with silica gel (60-120 or 100-200 mesh) were used for column chromatography. ${ }^{1} \mathrm{H}$ and ${ }^{13} \mathrm{C}$ NMR were recorded on 400 $\mathrm{MHz}, 500 \mathrm{MHz}$ and $100 \mathrm{MHz}, 125 \mathrm{MHz}$ spectrometer, respectively, in $\mathrm{CDCl}_{3}$ solvent using TMS as an internal standard. Chemical shifts are measured as ppm values relative to internal $\mathrm{CHCl}_{3} \delta 7.26$ or TMS $\delta 0.0$ for ${ }^{1} \mathrm{H}$ $\mathrm{NMR}$ and $\mathrm{CHCl}_{3} \delta 77$ for ${ }^{13} \mathrm{C}$ NMR. In ${ }^{1} \mathrm{H}$ NMR multiplicity defined as: $\mathrm{s}=$ singlet; $\mathrm{d}=$ doublet; $\mathrm{t}=$ triplet; $\mathrm{q}=$ quartet; $d d$ = doublet of doublet; $d d d=$ doublet of doublet of doublet; $d t$ = doublet of triplet; $m=$ multiplet; brs = broad singlet. Horiba sepa 300 polarimeter was used to record optical rotation using a $2 \mathrm{~mL}$ cell with a 10 $\mathrm{mm}$ path length. Alpha (Bruker) infrared spectrophotometer was used to record FTIR spectra. Either a TOF or a double focusing spectrometer was used to obtain high resolution mass spectra (HRMS) [ESI] ${ }^{+}$.

\section{(2S,4R)-5-(tert-Butyldiphenylsilyloxy)-N-((1R,2R)-1-hydroxy-1-phenylpropan-2-yl)-N,2,4-trimethylpentan-}

amide (10). $n$-BuLi was added drop wise $(29.18 \mathrm{~mL}$ of $2.5 \mathrm{M}$ solution in hexanes, $72.96 \mathrm{mmol})$ to a stirred solution of flame dried $\mathrm{LiCl}(3.73 \mathrm{~g}, 91.2 \mathrm{mmol}$ ) and diisopropylamine (11.69 mL, $82.08 \mathrm{mmol})$ in THF (10 mL) at $0{ }^{\circ} \mathrm{C}$, over $1 \mathrm{~h}$. This mixture was stirred at $0{ }^{\circ} \mathrm{C}$ for an additional $15 \mathrm{~min}$ before being cooled to $-78{ }^{\circ} \mathrm{C}$. $\mathrm{A}$ solution of $(1 R, 2 R)-(-)$-pseudoephedrine propionamide $(6.32 \mathrm{~g}, 38.30 \mathrm{mmol})$ in THF $(20 \mathrm{~mL})$ was then added to the reaction mixture very slowly using syringe pump. After being stirred at $-78{ }^{\circ} \mathrm{C}$ for 30 min the reaction mixture was warmed to $-20{ }^{\circ} \mathrm{C}$ and treated with a solution of the iodide $7(2.0 \mathrm{~g}, 9.12 \mathrm{mmol})$ in THF (10 mL). The reaction mixture was stirred at $-20{ }^{\circ} \mathrm{C}$ for $24 \mathrm{~h}$ and quenched with saturated aqueous solution of $\mathrm{NH}_{4} \mathrm{Cl}(5$ $\mathrm{mL})$. The reaction mixture was extracted with EtOAc $(2 \times 20 \mathrm{~mL})$. The combined organic extracts were washed with water $(5 \mathrm{~mL})$, brine $(5 \mathrm{~mL})$, dried over $\mathrm{Na}_{2} \mathrm{SO}_{4}$, filtered and concentrated under vacuo. The residue was purified by column chromatography ( $\left.\mathrm{SiO}_{2}, 25 \% \mathrm{EtOAc} / \mathrm{hexane}\right)$ to afford $10(2.40 \mathrm{~g}, 95 \%)$ as a colorless liquid. $\mathrm{R}_{f} 0.5$ (50\% EtOAc in hexanes); $[\alpha]_{D}{ }^{25}-42.1$ (c 0.96, $\mathrm{CHCl}_{3}$ ). IR (neat): $v_{\max } 3742,3393,3065,2931,1696,1620$, 1464, 1105, 819, 744, $700 \mathrm{~cm}^{-1} ;{ }^{1} \mathrm{H}$ NMR $\left(400 \mathrm{MHz}, \mathrm{CDCl}_{3}\right): \delta 7.67-7.64(\mathrm{~m}, 4 \mathrm{H}), 7.44-7.28(\mathrm{~m}, 11 \mathrm{H}), 4.60(\mathrm{~d}, \mathrm{~J}$ $7.4 \mathrm{~Hz}, 1 \mathrm{H}), 4.34$ (brs, 1H), $3.51(\mathrm{dd}, J 9.9,5.1 \mathrm{~Hz}, 1 \mathrm{H}), 3.42(\mathrm{dd}, J 9.9,5.8 \mathrm{~Hz}, 1 \mathrm{H}), 2.78(\mathrm{~s}, 3 \mathrm{H}), 2.68(\mathrm{~m}, 1 \mathrm{H})$, 1.76-1.60 (m, 2H), $1.18(\mathrm{~m}, 1 \mathrm{H}), 1.12(\mathrm{~d}, J 6.5 \mathrm{~Hz}, 3 \mathrm{H}), 1.06(\mathrm{~d}, J 6.7 \mathrm{~Hz}, 3 \mathrm{H}), 1.05(\mathrm{~m}, 1 \mathrm{H}), 1.05(\mathrm{~s}, 9 \mathrm{H}), 0.87(\mathrm{~d}, J$ $6.5,3 \mathrm{H}) ;{ }^{13} \mathrm{C} \mathrm{NMR}\left(100 \mathrm{MHz}, \mathrm{CDCl}_{3}\right): \delta 179.08,142.62,135.60,135.58,133.88,133.84,129.54,128.28,127.58$, $126.20,77.20,76.50,68.75,37.59,34.09,33.24,26.89,19.31,17.69,17.31,14.37 ; \mathrm{HRMS}(\mathrm{ESI}) \mathrm{m} / z$ [M + Na] ${ }^{+}$ calcd. for $\mathrm{C}_{33} \mathrm{H}_{45} \mathrm{NO}_{3} \mathrm{SiNa} 554.3039$, found 554.3060.

(2S,4R)-5-(tert-Butyldiphenylsilyloxy)-2,4-dimethylpentan-1-ol (6). To a stirred solution of diisopropylamine $(4.81 \mathrm{~mL}, 33.76 \mathrm{mmol})$ in THF $(20 \mathrm{~mL})$ at $0^{\circ} \mathrm{C}$ was added $n$-BuLi $(12.54 \mathrm{~mL}$ of $2.5 \mathrm{M}$ solution in hexanes, 31.36 $\mathrm{mmol}$ ) drop wise and the solution was stirred at $0{ }^{\circ} \mathrm{C}$ for an additional $15 \mathrm{~min}$. Then Borane-ammonia complex (90\%, $0.96 \mathrm{~g}, 31.36 \mathrm{mmol})$ was added to the solution. After stirring for $30 \mathrm{~min}$ at $0{ }^{\circ} \mathrm{C}$, the solution was warmed to $\mathrm{rt}$ and stirred for additional $30 \mathrm{~min}$. Then the reaction mixture was cooled to $0{ }^{\circ} \mathrm{C}$ and it was treated with a solution of amide $10(2.1 \mathrm{~g}, 3.94 \mathrm{mmol})$ in $10 \mathrm{~mL}$ of THF. After stirring for $4 \mathrm{~h}$ at room temperature, the reaction mixture was quenched with saturated aqueous $\mathrm{NH}_{4} \mathrm{Cl}(5 \mathrm{~mL})$ solution and extracted with EtOAc (2x50 mL). The combined organic extracts were washed with brine $(20 \mathrm{~mL})$ and dried over $\mathrm{Na}_{2} \mathrm{SO}_{4}$. 
Evaporation of the solvent under reduced pressure gave crude mass which on purification via silica gel column chromatography ( $\mathrm{SiO}_{2}, 17 \%$ EtOAc/hexanes) afforded 6 (980 mg, 90\% yield) as a colourless viscous liquid. $\mathrm{R}_{f}$ 0.6 (25\% EtOAc in hexanes); $[\alpha]_{\mathrm{D}}^{25}-2.04$ (c 1.23, $\mathrm{CHCl}_{3}$ ). IR (neat): $v_{\max } 2956,2860,1515,1466,1107,821,740$, $613 \mathrm{~cm}^{-1} ;{ }^{1} \mathrm{H}$ NMR $\left(500 \mathrm{MHz}, \mathrm{CDCl}_{3}\right): \delta$ 7.69-7.66 (m, 4H), 7.45-7.36 (m, 6H), $3.53(\mathrm{dd}, J 9.8,5.3 \mathrm{~Hz}, 1 \mathrm{H}), 3.48$ (dd, J 10.6, 5.1 Hz, 1H), 3.44(dd, J 9.8, $6.2 \mathrm{~Hz}, 1 \mathrm{H}), 3.35$ (dd, J 10.5, 6.6 Hz, 1H), $1.75(\mathrm{~m}, 1 \mathrm{H}), 1.64(\mathrm{~m}, 1 \mathrm{H}), 1.46$ $(\mathrm{m}, 1 \mathrm{H}), 1.34(\mathrm{~m}, 1 \mathrm{H}), 1.07(\mathrm{~s}, 9 \mathrm{H}), 0.97(\mathrm{~d}, J 6.6,3 \mathrm{H}), 0.90(\mathrm{~d}, J 6.7 \mathrm{~Hz}, 3 \mathrm{H}) ;{ }^{13} \mathrm{C} \mathrm{NMR}\left(125 \mathrm{MHz}^{\mathrm{CDCl}} 3\right): \delta$ 135.61, 133.95, 129.51, 127.56, 68.70, 68.26, 37.13, 33.14, 26.87, 19.27, 17.88, 17.39; HRMS (ESI) $\mathrm{m} / z$ [M + $\mathrm{Na}]^{+}$calcd. for $\mathrm{C}_{23} \mathrm{H}_{34} \mathrm{O}_{2} \mathrm{SiNa} 393.2226$, found 393.2221.

(R)-4-Benzyl-3-((2R,3S,4S,6R)-7-(tert-butyldiphenylsilyloxy)-3-hydroxy-2,4,6-trimethylheptanoyl)oxazolidin-

2-one (12). To a stirred solution of 6 (800 mg, $2.08 \mathrm{mmol})$ in $\mathrm{CH}_{2} \mathrm{Cl}_{2}(10 \mathrm{~mL}), \mathrm{NaHCO}_{3}(0.34 \mathrm{~g}, 4.16 \mathrm{mmol})$ was added at $0{ }^{\circ} \mathrm{C}$, followed by Dess-Martin periodinane $(1.32 \mathrm{~g}, 3.12 \mathrm{mmol})$ under nitrogen atmosphere and stirred for $2 \mathrm{~h}$ at room temperature. Saturated aqueous $\mathrm{NaHCO}_{3}(5 \mathrm{~mL})$ and $\mathrm{Na}_{2} \mathrm{~S}_{2} \mathrm{O}_{3}(7 \mathrm{~mL})$ were added to the reaction mixture and extracted with EtOAc $(2 \times 10 \mathrm{~mL})$. The organic phase was washed with water $(10 \mathrm{~mL})$, brine $(10 \mathrm{~mL})$, dried over $\mathrm{Na}_{2} \mathrm{SO}_{4}$ and concentrated in vacuo. The aldehyde, thus obtained, was used directly, for the next reaction without any further characterization.

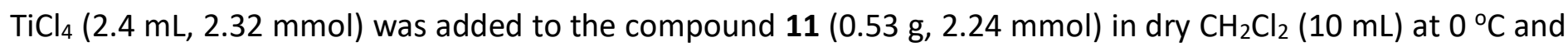
after $5 \mathrm{~min},(-)$-sparteine $(1.23 \mathrm{~mL}, 5.3 \mathrm{mmol})$ was added. After stirring at the same temperature for $20 \mathrm{~min}$, a solution of crude aldehyde in $\mathrm{CH}_{2} \mathrm{Cl}_{2}(5 \mathrm{~mL})$ was added under nitrogen atmosphere. After 10 min the reaction mixture was quenched with saturated aqueous $\mathrm{NH}_{4} \mathrm{Cl}$ solution $(5 \mathrm{~mL})$ and extracted with EtOAc $(2 \times 20 \mathrm{~mL})$. The combined organic layers were washed with $0.5 \mathrm{~N} \mathrm{HCl}(5 \mathrm{~mL})$, water $(5 \mathrm{~mL})$, brine $(5 \mathrm{~mL})$, dried over $\mathrm{Na}_{2} \mathrm{SO}_{4}$ and concentrated in vacuo. The residue was purified by column chromatography $\left(\mathrm{SiO}_{2}, 18 \% \mathrm{EtOAc} / \mathrm{hexanes}\right)$ to afford 12 (1.24 g, 96\% yield over two steps) as a colourless viscous liquid. $\mathrm{R}_{f} 0.2$ (20\% EtOAc in hexane); [ $\left.\alpha\right]_{D}{ }^{25}$ +15.88 (c 0.86, $\mathrm{CHCl}_{3}$ ). IR (neat): $v_{\max } 2927,1781,1694,1515,1462,1384,1206,1108,823,740,703 \mathrm{~cm}^{-1} ;{ }^{1} \mathrm{H}$ NMR $\left(400 \mathrm{MHz}_{\mathrm{CDCl}}\right): \delta$ 7.69-7.65 $(\mathrm{m}, 4 \mathrm{H}), 7.44-7.27(\mathrm{~m}, 9 \mathrm{H}), 7.22-7.18(\mathrm{~m}, 2 \mathrm{H}), 4.65(\mathrm{~m}, 1 \mathrm{H}), 4.21-4.14(\mathrm{~m}$, 2H), $3.97(\mathrm{~m}, 1 \mathrm{H}), 3.68(\mathrm{t}, J 5.5 \mathrm{~Hz}, 1 \mathrm{H}), 3.54(\mathrm{dd}, J$ 9.8, $5.0 \mathrm{~Hz}, 1 \mathrm{H}), 3.44(\mathrm{dd}, J 9.8,6.4 \mathrm{~Hz}, 1 \mathrm{H}), 3.24(\mathrm{dd}, J 13.4$, $3.4 \mathrm{~Hz}, 1 \mathrm{H}), 2.77(\mathrm{dd}, J 13.4,9.5 \mathrm{~Hz}, 1 \mathrm{H}), 2.34$ (brs, 1H), $1.78(\mathrm{~m}, 1 \mathrm{H}), 1.69-1.56(\mathrm{~m}, 2 \mathrm{H}), 1.49(\mathrm{~m}, 1 \mathrm{H}), 1.24(\mathrm{~d}, J$ $7.0 \mathrm{~Hz}, 3 \mathrm{H}), 1.06(\mathrm{~s}, 9 \mathrm{H}), 0.96,(\mathrm{~d}, J 6.7 \mathrm{~Hz}, 3 \mathrm{H}), 0.90(\mathrm{~d}, J 6.6 \mathrm{~Hz}, 3 \mathrm{H}) ;{ }^{13} \mathrm{C} \mathrm{NMR}\left(100 \mathrm{MHz}, \mathrm{CDCl}_{3}\right): \delta 177.13$, $152.84,135.68,135.65,135.10,133.97,129.54,129.46,128.98,127.62,127.43,74.93,68.46,66.06,55.16$, 40.22, 37.76, 37.11, 33.25, 32.86, 26.93, 19.31, 18.24, 15.23, 12.12; HRMS (ESI) $\mathrm{m} / \mathrm{z}[\mathrm{M}+\mathrm{Na}]^{+}$calcd. for $\mathrm{C}_{36} \mathrm{H}_{47} \mathrm{NO}_{5} \mathrm{SiNa} 624.3109$, found 624.3106.

(2S,3S,4S,6R)-7-(tert-Butyldiphenylsilyloxy)-2,4,6-trimethylheptane-1,3-diol (13). To a stirred solution of compound $12(1.1 \mathrm{~g}, 1.76 \mathrm{mmol})$ in dry ether $(25 \mathrm{~mL})$ at $0{ }^{\circ} \mathrm{C}$ were added one drop of distilled water followed by $\mathrm{LiBH}_{4}(77 \mathrm{mg}, 3.53 \mathrm{mmol}$ ) in portion wise. The reaction mixture was stirred at the same temperature for 10 min before being quenched with the careful addition of distilled water and extracted with EtOAc $(2 \times 20 \mathrm{~mL})$, the combined organic layers were washed with water $(10 \mathrm{~mL})$, brine $(10 \mathrm{~mL})$, dried over $\mathrm{Na}_{2} \mathrm{SO}_{4}$ and concentrated in vacuo. Purification of the residue by column chromatography $\left(\mathrm{SiO}_{2}, 25 \% \mathrm{EtOAc} / \mathrm{hexanes}\right)$ afforded 13 (680 mg, 96\% yield) as a colourless viscous liquid. $\mathrm{R}_{f} 0.3$ (30\% EtOAc in hexane); [ $\left.\alpha\right]_{\mathrm{D}}^{25}-3.6$ (c 1.01 , $\mathrm{CHCl}_{3}$ ). IR (neat): $v_{\max } 3856,3618,3393,2957,2859,1515,1427,1386,1107,1081,972,821,740,701 \mathrm{~cm}^{-1}$; ${ }^{1} \mathrm{H}$ NMR $\left(400 \mathrm{MHz}, \mathrm{CDCl}_{3}\right): \delta 7.68-7.64(\mathrm{~m}, 4 \mathrm{H}), 7.43-7.34(\mathrm{~m}, 6 \mathrm{H}), 3.65(\mathrm{~d}, J 4.8 \mathrm{~Hz}, 2 \mathrm{H}), 3.52(\mathrm{dd}, J 9.8,4.9 \mathrm{~Hz}$, $1 \mathrm{H}), 3.47-3.40(\mathrm{~m}, 2 \mathrm{H}), 2.0$ (brs, $1 \mathrm{H}), 1.84(\mathrm{~m}, 1 \mathrm{H}), 1.73(\mathrm{~m}, 1 \mathrm{H}), 1.60(\mathrm{~m}, 1 \mathrm{H}), 1.46(\mathrm{~m}, 1 \mathrm{H}), 1.05(\mathrm{~s}, 9 \mathrm{H}), 0.95$ (d, J $6.8 \mathrm{~Hz}, 3 \mathrm{H}), 0.92$ (d, J $6.9 \mathrm{~Hz}, 3 \mathrm{H}), 0.91(\mathrm{~d}, J 6.6 \mathrm{~Hz}, 3 \mathrm{H}), 0.85(\mathrm{~m}, 1 \mathrm{H}) ;{ }^{13} \mathrm{C} \mathrm{NMR}\left(100 \mathrm{MHz}, \mathrm{CDCl}_{3}\right): \delta 135.64$, 135.58, 133.92, 133.87, 129.54, 127.58, 78.11, 68.18, 67.50, 37.18, 36.60, 33.64, 33.14, 26.89, 19.28, 18.43, 15.69, 10.29; HRMS (ESI) $m / z$ [M + H] calcd. for $\mathrm{C}_{26} \mathrm{H}_{41} \mathrm{O}_{3} \mathrm{Si} 429.2821$, found 429.2825 . 
tert-Butyl((2R,4S)-4-((4S,5S)-2-(4-methoxyphenyl)-5-ethyl-1,3-dioxan-4-yl)-2-methylpentyloxy)diphenylsilane (14). Freshly prepared PMP acetal $(0.36 \mathrm{~mL}, 2.09 \mathrm{mmol})$, followed by CSA (30 $\mathrm{mg}, 0.14 \mathrm{mmol}$ ) were added to the compound $13(0.6 \mathrm{~g}, 1.40 \mathrm{mmol})$ in anhydrous $\mathrm{CH}_{2} \mathrm{Cl}_{2}(25 \mathrm{~mL})$ at $0{ }^{\circ} \mathrm{C}$. The resulting reaction mixture was stirred for $12 \mathrm{~h}$ at ambient temperature. The reaction mixture was quenched with saturated aqueous $\mathrm{NaHCO}_{3}$ solution $(5 \mathrm{~mL})$ and extracted with EtOAc $(2 \times 15 \mathrm{~mL})$. Combined organic layers were washed with water $(10 \mathrm{~mL})$, brine $(10 \mathrm{~mL})$, dried over $\mathrm{Na}_{2} \mathrm{SO}_{4}$ and concentrated in vacuo. The residue was purified by column chromatography $\left(\mathrm{SiO}_{2}, 12 \%\right.$ EtOAc/hexanes) to afford $14\left(0.72 \mathrm{~g}, 94 \%\right.$ yield) as a colourless liquid. $\mathrm{R}_{f}$ 0.7 (30\% EtOAc in hexanes); $[\alpha]_{D}{ }^{25}-8.90$ (c $1.94, \mathrm{CHCl}_{3}$ ). IR (neat): $v_{\max } 2956,2853,1616,1515,1387,1246$, $1108,1004,822,740,701,613 \mathrm{~cm}^{-1} ;{ }^{1} \mathrm{H}$ NMR $\left(400 \mathrm{MHz}, \mathrm{CDCl}_{3}\right): \delta 7.70-7.66(\mathrm{~m}, 4 \mathrm{H}), 7.46-7.36(\mathrm{~m}, 8 \mathrm{H}), 6.90(\mathrm{~d}$, J $8.6 \mathrm{~Hz}, 2 \mathrm{H}), 5.43(\mathrm{~s}, 1 \mathrm{H}), 4.01(\mathrm{~s}, 2 \mathrm{H}), 3.81(\mathrm{~s}, 3 \mathrm{H}), 3.60(\mathrm{dd}, J 10.0,4.6 \mathrm{~Hz}, 1 \mathrm{H}), 3.46(\mathrm{dd}, J 9.8,6.3 \mathrm{~Hz}, 1 \mathrm{H}), 3.39$ (dd, J 9.6, $1.9 \mathrm{~Hz}, 1 \mathrm{H}), 1.82(\mathrm{~m}, 1 \mathrm{H}), 1.75-1.66(\mathrm{~m}, 2 \mathrm{H}), 1.48(\mathrm{~m}, 1 \mathrm{H}), 1.10(\mathrm{~d}, J 7.0 \mathrm{~Hz}, 3 \mathrm{H}), 1.08(\mathrm{~s}, 9 \mathrm{H}), 1.0(\mathrm{~d}, J$ $6.6 \mathrm{~Hz}, 3 \mathrm{H}), 0.95(\mathrm{~d}, J 6.4 \mathrm{~Hz}, 3 \mathrm{H}), 0.79(\mathrm{~m}, 1 \mathrm{H}) ;{ }^{13} \mathrm{C} \mathrm{NMR}\left(100 \mathrm{MHz}, \mathrm{CDCl}_{3}\right): \delta 159.73,135.65,135.58,133.91$, $133.84,131.72,129.54,129.51,127.56,127.21,113.52,101.65,85.06,67.53,55.26,35.13,32.69,32.23$, 29.99, 19.29, 19.09, 16.24, 11.19; HRMS (ESI) $\mathrm{m} / z$ [M + H] ${ }^{+}$calcd. for $\mathrm{C}_{34} \mathrm{H}_{47} \mathrm{O}_{4} \mathrm{Si}$ 547.3233, found 547.3238.

(2R,4S)-4-((4S,5S)-2-(4-Methoxyphenyl)-5-methyl-1,3-dioxan-4-yl)-2-methylpentan-1-ol (15). TBAF (1M solution in THF $1.3 \mathrm{~mL}, 1.3 \mathrm{mmol}$ ) was added to a stirred solution of compound 14 (0.65 g, $1.18 \mathrm{mmol})$ in dry $\operatorname{THF}(15 \mathrm{~mL})$, at $0{ }^{\circ} \mathrm{C}$. Reaction mixture was warmed to room temperature and stirred for $12 \mathrm{~h}$. It was quenched with saturated aqueous $\mathrm{NH}_{4} \mathrm{Cl}$ solution $(5 \mathrm{~mL})$, extracted with EtOAc $(2 \times 15 \mathrm{~mL})$, washed with brine $(5 \mathrm{~mL})$, dried over $\mathrm{Na}_{2} \mathrm{SO}_{4}$ and concentrated in vacuo. The residue was purified by column chromatography $\left(\mathrm{SiO}_{2}, 16 \%\right.$ EtOAc/hexanes) to afford 15 (333 mg, 91\% yield) as a colourless viscous liquid. $\mathrm{R}_{f} 0.4$ (20\% EtOAc in hexanes); $[\alpha]_{D}{ }^{25}-2.81$ (c $0.76, \mathrm{CHCl}_{3}$ ). IR (neat): $v_{\max } 2969,2854,1615,1516,1248,1110,1034,826,739,703 \mathrm{~cm}^{-1} ;{ }^{1} \mathrm{H}$ NMR (400 MHz, $\left.\mathrm{CDCl}_{3}\right): \delta$ 7.42-7.37 (m, 2H), 6.91-6.86 (m, 2H), $5.42(\mathrm{~s}, 1 \mathrm{H}), 4.02(\mathrm{~s}, 2 \mathrm{H}), 3.79(\mathrm{~s}, 3 \mathrm{H}), 3.51-3.38$ $(\mathrm{m}, 3 \mathrm{H}), 1.81-1.63(\mathrm{~m}, 5 \mathrm{H}), 1.15(\mathrm{~d}, J 6.8 \mathrm{~Hz}, 3 \mathrm{H}), 0.92(\mathrm{~d}, J 6.4 \mathrm{~Hz}, 3 \mathrm{H}), 0.86(\mathrm{~d}, J 6.8 \mathrm{~Hz}, 3 \mathrm{H}) ;{ }^{13} \mathrm{C} \mathrm{NMR}(100$ $\left.\mathrm{MHz}_{1} \mathrm{CDCl}_{3}\right): \delta 159.86,131.28,127.23,113.61,101.88,85.06,73.93,67.16,55.22,37.42,33.67,32.38,30.08$, 18.62, 15.63, 10.83; HRMS (ESI) $\mathrm{m} / z$ [M + Na] ${ }^{+}$calcd. for $\mathrm{C}_{18} \mathrm{H}_{28} \mathrm{O}_{4} \mathrm{SiNa} 331.1871$, found 331.1874 .

(4R,6S)-6-((4S,5S)-2-(4-Methoxyphenyl)-5-methyl-1,3-dioxan-4-yl)-4-methylhept-1-en-3-ol (16). To a stirred solution of $15(0.30 \mathrm{~g}, 1.94 \mathrm{mmol})$ in $\mathrm{CH}_{2} \mathrm{Cl}_{2}(10 \mathrm{~mL}), \mathrm{NaHCO}_{3}(0.16 \mathrm{~g}, 1.94 \mathrm{mmol})$ was added at $0{ }^{\circ} \mathrm{C}$, followed by Dess-Martin periodinane $(0.82 \mathrm{~g}, 1.94 \mathrm{mmol})$ under nitrogen atmosphere. The reaction mixture was allowed to come to room temperature and stirred for $2 \mathrm{~h}$ before being quenched with saturated $\mathrm{Na}_{2} \mathrm{~S}_{2} \mathrm{O}_{3}(5$ $\mathrm{mL})$ and $\mathrm{NaHCO}_{3}(3 \mathrm{~mL})$ and extracted with EtOAc $(2 \times 10 \mathrm{~mL})$. The combined organic layers were washed with water $(5 \mathrm{~mL})$, brine $(5 \mathrm{~mL})$, dried over anhydrous $\mathrm{Na}_{2} \mathrm{SO}_{4}$. Evaporation of the solvent furnished crude aldehyde, which was passed through a short pad of silica gel and used as such for the next reaction.

To a stirred solution of crude aldehyde in dry THF $(10 \mathrm{~mL})$, vinyl magnesium bromide (1M solution in THF 1.94 $\mathrm{mL}, 1.94 \mathrm{mmol}$ ) was added at $0{ }^{\circ} \mathrm{C}$. Reaction mixture was warmed to room temperature and stirred for $1 \mathrm{~h}$. It was quenched with saturated aqueous $\mathrm{NH}_{4} \mathrm{Cl}$ solution $(5 \mathrm{~mL})$, extracted with EtOAc $(2 \times 10 \mathrm{~mL})$. The combined organic layers were washed with brine $(10 \mathrm{~mL})$, dried over $\mathrm{Na}_{2} \mathrm{SO}_{4}$ and concentrated in vacuo. The residue was purified by column chromatography ( $\mathrm{SiO}_{2}, 14 \% \mathrm{EtOAc/hexanes)} \mathrm{to} \mathrm{afford} 16$ ( $0.27 \mathrm{~g}, 84 \%$ yield) as a colourless viscous liquid. $\mathrm{R}_{f} 0.6$ (20\% EtOAc in hexanes); $[\alpha]_{\mathrm{D}}{ }^{25}-2.85$ (c $0.7, \mathrm{CHCl}_{3}$ ). IR (neat): $v_{\max } 2856,1514,1465,1248$, 1035, $621 \mathrm{~cm}^{-1}$; ${ }^{1} \mathrm{H}$ NMR $\left(500 \mathrm{MHz}, \mathrm{CDCl}_{3}\right): \delta$ 7.44-7.41 (m, 2H), 6.90-6.86 (m, 2H), 5.89 (ddd, J 16.0, 10.7, 5.4 $\mathrm{Hz}, 1 \mathrm{H}) 5.44(\mathrm{~s}, 1 \mathrm{H}), 5.23(\mathrm{dt}, J 17.3,1.6 \mathrm{~Hz}, 1 \mathrm{H}), 5.15(\mathrm{dt}, J 10.5,1.6 \mathrm{~Hz}, 1 \mathrm{H}), 4.16(\mathrm{~m}, 1 \mathrm{H}), 4.03-4.01(\mathrm{~m}, 2 \mathrm{H})$, $3.79(\mathrm{~s}, 3 \mathrm{H}), 3.44(\mathrm{dd}, J$ 9.6, $2.2 \mathrm{~Hz}, 1 \mathrm{H}), 1.87-1.72(\mathrm{~m}, 3 \mathrm{H}), 1.66$ (ddd, J 13.3, 9.5, 3.2 Hz, $1 \mathrm{H}), 1.18(\mathrm{~d}, J 7.0 \mathrm{~Hz}$, $3 \mathrm{H}), 1.01$ (d, J $6.4 \mathrm{~Hz}, 3 \mathrm{H}) 0.89$ (d, J $6.8 \mathrm{~Hz}, 3 \mathrm{H}), 0.77$ (ddd, J 15.3, 10.9, 4.4 Hz, 1H); ${ }^{13} \mathrm{C} \mathrm{NMR}\left(125 \mathrm{MHz}, \mathrm{CDCl}_{3}\right)$ : $\delta 159.75,140.43,131.73,127.23,114.58,113.54,101.69,84.96,73.98,73.50,55.27,34.96,34.54,32.25$, 30.11, 16.27, 15.09, 11.15; HRMS (ESI) $\mathrm{m} / z$ [M + Na] ${ }^{+}$calcd. for $\mathrm{C}_{20} \mathrm{H}_{30} \mathrm{O}_{4} \mathrm{Na}$ 357.2047, found 357.2051. 
tert-Butyl((4R,6S)-6-((4S,5S)-2-(4-methoxyphenyl)-5-ethyl-1,3-dioxan-4-yl)-4-methylhept-1-en-3-yloxy) dimethylsilane (17). 2,6-Lutidine $(0.26 \mathrm{~mL}, 2.26 \mathrm{mmol})$ and TBSOTf $(0.14 \mathrm{~mL}, 0.83 \mathrm{mmol})$ were added sequentially to a stirred solution of compound $16(0.25 \mathrm{~g}, 0.75 \mathrm{mmol})$ in $\mathrm{CH}_{2} \mathrm{Cl}_{2}(7 \mathrm{~mL})$ at $0{ }^{\circ} \mathrm{C}$. After $2 \mathrm{~h}$, reaction was quenched with saturated $\mathrm{NH}_{4} \mathrm{Cl}$ solution $(5 \mathrm{~mL})$, the reaction mixture was extracted with EtOAc $(2 \times 10 \mathrm{~mL})$. The organic layer was washed with saturated aqueous $\mathrm{CuSO}_{4}$ solution $(5 \mathrm{~mL})$, brine $(5 \mathrm{~mL}), \mathrm{dried}$ over $\mathrm{Na}_{2} \mathrm{SO}_{4}$ and concentrated in vacuo. The residue was purified by column chromatography $\left(\mathrm{SiO}_{2}, 3 \%\right.$ EtOAc/hexanes) to afford 17 ( $0.32 \mathrm{~g}, 93 \%$ yield) as a colourless viscous liquid. $\mathrm{R}_{f} 0.8$ (10\% EtOAc in hexanes); $[\alpha]_{\mathrm{D}}{ }^{25}+5.2$ (c 0.52, $\mathrm{CHCl}_{3}$ ). IR (neat): $v_{\max } 2915,2858,1515,1427,1386,972,822,740,624 \mathrm{~cm}^{-1} ;{ }^{1} \mathrm{H} \mathrm{NMR}(400$ $\left.\mathrm{MHz}, \mathrm{CDCl}_{3}\right): \delta 7.42-7.38(\mathrm{~m}, 2 \mathrm{H}), 6.88-6.84(\mathrm{~m}, 2 \mathrm{H}), 5.82(\mathrm{ddd}, J 17.0,10.4,6.5 \mathrm{~Hz}, 1 \mathrm{H}) 5.43(\mathrm{~s}, 1 \mathrm{H}), 5.16-5.06$ $(\mathrm{m}, 2 \mathrm{H}), 4.20-4.01(\mathrm{~m}, 2 \mathrm{H}), 3.80(\mathrm{~s}, 3 \mathrm{H}), 3.39(\mathrm{dd}, J$ 9.6, $2.2 \mathrm{~Hz}, 1 \mathrm{H}), 1.83-1.60(\mathrm{~m}, 5 \mathrm{H}), 1.16(\mathrm{~d}, J 6.9 \mathrm{~Hz}, 3 \mathrm{H})$, $1.01(\mathrm{~d}, J 6.4 \mathrm{~Hz}, 3 \mathrm{H}), 0.91(\mathrm{~d}, J 6.7 \mathrm{~Hz}, 3 \mathrm{H}), 0.89(\mathrm{~s}, 9 \mathrm{H}), 0.63(\mathrm{~m}, 1 \mathrm{H}) 0.04(\mathrm{~s}, 3 \mathrm{H}), 0.01(\mathrm{~s}, 3 \mathrm{H}) ;{ }^{13} \mathrm{C} \mathrm{NMR}(125$ $\left.\mathrm{MHz}, \mathrm{CDCl}_{3}\right): \delta 159.74,139.68,131.82,127.24,115.05,113.53,101.73,85.30,77.64,74.02,55.28,37.68$, 34.30, 33.36, 30.23, 25.9, 17.18, 16.92, 11.53, -4.05, -4.86; HRMS (ESI) $\mathrm{m} / z$ [M + H] calcd. for $\mathrm{C}_{26} \mathrm{H}_{45} \mathrm{O}_{4} \mathrm{Si}$ 449.3089 , found 449.3087.

(3R,4S,6R)-7-(tert-Butyldimethylsilyloxy)-3-(4-methoxybenzyloxy)-4,6-dimethylnon-8-enal (4). To a stirred solution of compound $17(0.270 \mathrm{~g}, 0.60 \mathrm{mmol})$ in dry $\mathrm{CH}_{2} \mathrm{Cl}_{2}(8 \mathrm{~mL})$ at $-40{ }^{\circ} \mathrm{C}$, DIBAL-H (1.5 M solution in toluene, $1.6 \mathrm{~mL}, 2.4 \mathrm{mmol}$ ) was added drop wise under nitrogen atmosphere. After stirring for $0.5 \mathrm{~h}$ at the same temperature, the reaction mixture was slowly brought to $0{ }^{\circ} \mathrm{C}$ and stirred for $2 \mathrm{~h}$. Dry $\mathrm{MeOH}(3 \mathrm{~mL}) \mathrm{was}$ added drop wise at $-78{ }^{\circ} \mathrm{C}$ to quench the reaction mixture, and stirred for $0.5 \mathrm{~h}$ at the same temperature, then added potassium sodium tartrate, stirred at room temperature for $1 \mathrm{~h}$ and extracted with EtOAc $(2 \times 10 \mathrm{~mL})$. The combined organic extracts were washed with brine $(10 \mathrm{~mL})$, dried over $\mathrm{Na}_{2} \mathrm{SO}_{4}$ and concentrated in vacuo. The residue was purified by column chromatography $\left(\mathrm{SiO}_{2}, 25 \%\right.$ EtOAc/hexanes) to afford primary alcohol $4 \mathrm{a}$ (220 mg, 90\% yield) as a colourless viscous liquid. $\mathrm{R}_{f} 0.2$ (30\% EtOAc in hexane); $[\alpha]_{\mathrm{D}}{ }^{25}+4.90$ (c $\left.1.03, \mathrm{CHCl}_{3}\right)$. IR (neat): $v_{\max } 2925,2855,1699,1515,1463,1248,1036,835,775 \mathrm{~cm}^{-1} ;{ }^{1} \mathrm{H}$ NMR $\left(500 \mathrm{MHz}, \mathrm{CDCl}_{3}\right): \delta 7.28-7.25$ $(\mathrm{m}, 2 \mathrm{H}), 6.88-6.84(\mathrm{~m}, 2 \mathrm{H}), 5.77(\mathrm{ddd}, J 16.4,10.4,6.5 \mathrm{~Hz}, 1 \mathrm{H}), 5.11(\mathrm{dt}, J 17.1,3.1, \mathrm{~Hz}, 1 \mathrm{H}), 5.06(\mathrm{dt}, J 10.3,3.0$ $\mathrm{Hz}, 1 \mathrm{H}), 4.51(\mathrm{ABq}, J 10.9 \mathrm{~Hz}, 2 \mathrm{H}), 3.89(\mathrm{~m}, 1 \mathrm{H}), 3.79(\mathrm{~s}, 3 \mathrm{H}), 3.62(\mathrm{dd}, J 10.6,7.0 \mathrm{~Hz}, 1 \mathrm{H}), 3.53(\mathrm{dd}, J 10.6,5.8$ $\mathrm{Hz}, 1 \mathrm{H}), 3.30(\mathrm{t}, J 4.5,1 \mathrm{H}), 2.01(\mathrm{~m}, 1 \mathrm{H}), 1.90-1.81(\mathrm{~m}, 2 \mathrm{H}), 1.66-1.58(\mathrm{~m}, 2 \mathrm{H}), 1.00(\mathrm{~d}, J 6.8 \mathrm{~Hz}, 3 \mathrm{H}), 0.95(\mathrm{~d}, J$ $6.9 \mathrm{~Hz}, 3 \mathrm{H}), 0.88(\mathrm{~s}, 9 \mathrm{H}), 0.87(\mathrm{~d}, J 6.8 \mathrm{~Hz}, 3 \mathrm{H}), 0.02(\mathrm{~s}, 3 \mathrm{H}), 0.00(\mathrm{~s}, 3 \mathrm{H}) ;{ }^{13} \mathrm{C} \mathrm{NMR}\left(125 \mathrm{MHz}, \mathrm{CDCl}_{3}\right): \delta 159.08$, 139.99, 131.07, 114.81, 113.72, 83.90, 77.88, 73.93, 66.46, 55.24, 37.96, 37.50, 32.97, 25.90, 18.25, 16.41, 15.90, -4.18, -4.86; HRMS (ESI) $m / z[M+N a]^{+}$calcd. for $\mathrm{C}_{26} \mathrm{H}_{46} \mathrm{O}_{4} \mathrm{SiNa} 459.2911$, found 459.2914 .

To a stirred solution of primary alcohol $(0.1 \mathrm{~g}, 0.22 \mathrm{mmol})$ in $\mathrm{CH}_{2} \mathrm{Cl}_{2}(3 \mathrm{~mL}), \mathrm{NaHCO}_{3}(0.37 \mathrm{mg}, 0.44 \mathrm{mmol})$ was added at $0^{\circ} \mathrm{C}$, followed by Dess-Martin periodinane $(0.18 \mathrm{mg}, 0.44 \mathrm{mmol})$ under nitrogen atmosphere. The reaction mixture was allowed to attain room temperature and stirred for $2 \mathrm{~h}$. Saturated $\mathrm{Na}_{2} \mathrm{~S}_{2} \mathrm{O}_{3}(10 \mathrm{~mL})$ and $\mathrm{NaHCO}_{3}(2 \mathrm{~mL})$ were added to quench the reaction mixture. After stirring $15 \mathrm{~min}$ the reaction mixture was extracted with EtOAc $(2 \times 20 \mathrm{~mL})$. The organic phase was washed with water $(20 \mathrm{~mL})$, brine $(20 \mathrm{~mL})$, dried over $\mathrm{Na}_{2} \mathrm{SO}_{4}$ and concentrated in vacuo. The aldehyde 4 thus obtained was directly used, after passing through a short pad of silica, for the next reaction without any further characterization.

$(2 S, 4 R, 5 R)$-5-Hydroxy-4-methyl-3-oxohexan-2-yl benzoate (8). To a stirred solution of $c-\mathrm{Hex}_{2} \mathrm{BCl}(14.54 \mathrm{~mL}$, $14.54 \mathrm{mmol})$ in $\mathrm{Et}_{2} \mathrm{O}(20 \mathrm{~mL})$ at $-78{ }^{\circ} \mathrm{C}$ was added $\mathrm{Me}_{2} \mathrm{NEt}(1.68 \mathrm{~mL}, 19.4 \mathrm{mmol})$, followed by ketone 9 (2 $\mathrm{g}, 9.7$ $\mathrm{mmol})$ in $\mathrm{Et}_{2} \mathrm{O}(10 \mathrm{~mL})$. The reaction mixture was warmed to $-10{ }^{\circ} \mathrm{C}$ for first $30 \mathrm{~min}$ and then to $0{ }^{\circ} \mathrm{C}$ for next 1 $\mathrm{h}$ before being cooled to $-78^{\circ} \mathrm{C}$. The commercially available acetaldehyde $(2.70 \mathrm{~mL}, 48.48 \mathrm{mmol})$ was added and stirred for further $2 \mathrm{~h}$ at the same temperature. Then the reaction mixture temperature was raised to -20 ${ }^{\circ} \mathrm{C}$ and stirred for $14 \mathrm{~h}$. The reaction was quenched at $0{ }^{\circ} \mathrm{C}$ by addition of $\mathrm{MeOH}(10 \mathrm{~mL})$ and $\mathrm{p}^{\mathrm{H}} 7$ buffer (10 $\mathrm{mL}), \mathrm{H}_{2} \mathrm{O}_{2}(5 \mathrm{~mL}, 30 \%)$ was then added and the stirring continued for $1 \mathrm{~h}$ and extracted with EtOAc (3x50mL). 
The combined organic extracts were washed with water $(10 \mathrm{~mL})$, brine $(5 \mathrm{~mL})$ and dried over $\mathrm{Na}_{2} \mathrm{SO}_{4}$ and concentrated in vacuo. The residue was purified by column chromatography $\left(\mathrm{SiO}_{2}, 8 \% \mathrm{EtOAc} / \mathrm{hexanes}\right)$ to afford 8 ( $2.06 \mathrm{~g}, 96 \%$ yield) as a colourless solid. $\mathrm{R}_{f} 0.7$ (20\% EtOAc in hexanes); $[\alpha]_{D}{ }^{25}+30.0$ (c $0.75, \mathrm{CHCl}_{3}$ ). IR (neat): $V_{\max } 2945,1720,1515,1454,1262,1116,1003,707 \mathrm{~cm}^{-1} ;{ }^{1} \mathrm{H} N M R\left(500 \mathrm{MHz}, \mathrm{CDCl}_{3}\right): \delta 8.08(\mathrm{~m}, 2 \mathrm{H})$, $7.58(\mathrm{~m}, 1 \mathrm{H}), 7.45-7.44(\mathrm{~m}, 2 \mathrm{H}), 5.44(\mathrm{q}, J 7.1 \mathrm{~Hz}, 1 \mathrm{H}), 3.98(\mathrm{dq}, J 13.7,6.4 \mathrm{~Hz}, 1 \mathrm{H}), 2.80(\mathrm{p}, J 7.3 \mathrm{~Hz}, 1 \mathrm{H}), 2.16$ (brs, 1H), 1.57 (d, J $7.1 \mathrm{~Hz}, 3 \mathrm{H}), 1.25(\mathrm{~d}, J 7.3 \mathrm{~Hz}, 3 \mathrm{H}), 1.22$ (d, J $6.2 \mathrm{~Hz}, 3 \mathrm{H}) ;{ }^{13} \mathrm{C} \mathrm{NMR}\left(125 \mathrm{MHz}, \mathrm{CDCl}_{3}\right): \delta$ 211.72, 165.86, 133.36, 129.77, 129.39, 128.45, 74.48, 69.45, 49.91, 20.84, 15.87, 14.40; HRMS (ESI) m/z [M + $\mathrm{Na}]^{+}$calcd. for $\mathrm{C}_{14} \mathrm{H}_{18} \mathrm{O}_{4} \mathrm{Na} 273.1093$, found 273.1097 .

(2S,4R,5R)-5-(tert-Butyldimethylsilyloxy)-4-methyl-3-oxohexan-2-yl benzoate (18). To a stirred solution of compound 8 (1.9 g, $7.59 \mathrm{mmol})$ in $\mathrm{CH}_{2} \mathrm{Cl}_{2}(30 \mathrm{~mL})$ at $0{ }^{\circ} \mathrm{C}, 2$,6-lutidine $(2.64 \mathrm{~mL}, 22.7$ mmol) was added followed by TBSOTf $(1.9 \mathrm{~mL}, 8.35 \mathrm{mmol})$ and stirred for $15 \mathrm{~min}$. The reaction was quenched with saturated aqueous $\mathrm{NH}_{4} \mathrm{Cl}$ solution $(20 \mathrm{~mL})$, the reaction mixture was extracted with EtOAc $(2 \times 30 \mathrm{~mL})$, washed with saturated aqueous $\mathrm{CuSO}_{4}$ solution $(20 \mathrm{~mL})$, brine $(20 \mathrm{~mL})$, dried over $\mathrm{Na}_{2} \mathrm{SO}_{4}$ and concentrated in vacuo. The residue was purified by column chromatography $\left(\mathrm{SiO}_{2}, 5 \% \mathrm{EtOAc/hexanes)}\right.$ to afford 18 ( $2.57 \mathrm{~g}, 92 \%$ yield $)$ as a colourless liquid. $\mathrm{R}_{f} 0.8$ (20\% EtOAc in hexanes); $[\alpha]_{D}{ }^{25}-14.00$ (c 0.68, $\mathrm{CHCl}_{3}$ ). IR (neat): $v_{\max } 2975,1720,1515$, $1454,1262,1116,1003,771,707 \mathrm{~cm}^{-1} ;{ }^{1} \mathrm{H}$ NMR $\left(500 \mathrm{MHz}, \mathrm{CDCl}_{3}\right): \delta 8.09-8.06(\mathrm{~m}, 2 \mathrm{H}), 7.57(\mathrm{~m}, 1 \mathrm{H}), 7.47-7.43$ $(\mathrm{m}, 2 \mathrm{H}), 5.41(\mathrm{q}, J 6.8 \mathrm{~Hz}, 1 \mathrm{H}), 4.05(\mathrm{~m}, 1 \mathrm{H}), 2.84(\mathrm{dq}, J 8.4,7.1 \mathrm{~Hz}, 1 \mathrm{H}), 1.51(\mathrm{~d}, J 7.0 \mathrm{~Hz}, 3 \mathrm{H}), 1.14(\mathrm{~d}, J 6.2 \mathrm{~Hz}$, $3 \mathrm{H}), 1.10(\mathrm{~d}, J 7.0 \mathrm{~Hz}, 3 \mathrm{H}), 0.83(\mathrm{~s}, 9 \mathrm{H}), 0.03(\mathrm{~s}, 3 \mathrm{H}),-0.03(\mathrm{~s}, 3 \mathrm{H}) ;{ }^{13} \mathrm{C} \mathrm{NMR}\left(125 \mathrm{MHz}, \mathrm{CDCl}_{3}\right): \delta 209.40,165.78$, 133.19, 129.81, 128.39, 75.08, 70.12, 50.58, 25.81, 21.15, 17.87, 15.24, 13.76, -4.69, -4.84; HRMS (ESI) $\mathrm{m} / z$ [M $+\mathrm{Na}]^{+}$calcd. for $\mathrm{C}_{20} \mathrm{H}_{32} \mathrm{O}_{4} \mathrm{SiNa} 388.2049$, found 388.2052.

(2S,4S,5R)-5-(tert-Butyldimethylsilyloxy)-4-methylhexane-2,3-diol (19). To a stirred solution of the protected aldol product $18(6.3 \mathrm{mmol})$ in THF $(25 \mathrm{~mL})$ at $-78{ }^{\circ} \mathrm{C}$ was added $\mathrm{LiBH}_{4}(2.74 \mathrm{~g}, 126.18 \mathrm{mmol})$. The reaction mixture was warmed slowly to room temperature and stirred for $21 \mathrm{~h}$. Then the reaction mixture was cooled to $0^{\circ} \mathrm{C}$ and quenched with the careful addition of $\mathrm{H}_{2} \mathrm{O}$. The mixture was extracted with EtOAc $(2 \times 25 \mathrm{~mL})$ and the combined organic extracts were washed with brine $(20 \mathrm{~mL})$, dried over $\mathrm{Na}_{2} \mathrm{SO}_{4}$ and concentrated in vacuo. The residue was purified by column chromatography $\left(\mathrm{SiO}_{2}, 18 \%\right.$ EtOAc/hexanes) to afford 19 (1.52 g, $92 \%$ yield) as a colourless viscous liquid. $\mathrm{R}_{f} 0.3$ (20\% EtOAc in hexanes); $[\alpha]_{\mathrm{D}}{ }^{25}-11.27$ (c $1.1, \mathrm{CHCl}_{3}$ ). IR (neat): $v_{\max }$ 3360, 2958, 2893, 1612, 1465, 1251, 1062, 838, 775, $688 \mathrm{~cm}^{-1} ;{ }^{1} \mathrm{H} \mathrm{NMR}\left(400 \mathrm{MHz}, \mathrm{CDCl}_{3}\right): \delta 3.89(\mathrm{p}, J 6.2 \mathrm{~Hz}$, $1 \mathrm{H}), 3.80(\mathrm{~m} 1 \mathrm{H}), 3.58(\mathrm{dd}, J=8.2,3.9 \mathrm{~Hz}, 1 \mathrm{H}), 3.42(\mathrm{~s}, 1 \mathrm{H}), 2.64(\mathrm{brs}, 1 \mathrm{H}), 1.64(\mathrm{~m}, 1 \mathrm{H}), 1.58(\mathrm{~m}, 1 \mathrm{H}), 1.20(\mathrm{~d}, J$ $6.2 \mathrm{~Hz}, 3 \mathrm{H}), 1.16(\mathrm{~d}, J 6.3 \mathrm{~Hz}, 3 \mathrm{H}), 0.90(\mathrm{~s}, 9 \mathrm{H}), 0.81$ (d, J $6.9 \mathrm{~Hz}, 3 \mathrm{H}), 0.11(\mathrm{~s}, 3 \mathrm{H}), 0.10(\mathrm{~s}, 3 \mathrm{H}) ;{ }^{13} \mathrm{C} \mathrm{NMR}(100$ $\mathrm{MHz}_{\mathrm{CDCl}}$ ): $\delta$ 73.17, 67.97, 42.98, 25.79, 21.40, 17.93, 16.24, 12.27, -4.22, -4.87; HRMS (ESI) $\mathrm{m} / \mathrm{z}[\mathrm{M}+\mathrm{H}]^{+}$ calcd. for $\mathrm{C}_{13} \mathrm{H}_{31} \mathrm{O}_{3} \mathrm{Si} 263.2048$, found 263.2045.

tert-Butyl((2R,3S,E)-5-iodo-3-methylpent-4-en-2-yloxy)dimethylsilane (20). To a stirred solution of 1,2-diol 19 (5.33 mmol) in $\mathrm{MeOH}(10 \mathrm{~mL})$ and $\mathrm{H}_{2} \mathrm{O}(5 \mathrm{~mL})$ at $0{ }^{\circ} \mathrm{C}$ was added $\mathrm{NalO}_{4}(3.42 \mathrm{~g}, 15.99 \mathrm{mmol})$. The reaction mixture was stirred at room temperature for $30 \mathrm{~min}$. Then it was diluted with $\mathrm{H}_{2} \mathrm{O}(15 \mathrm{~mL})$ and extracted with EtOAc $(2 \times 20 \mathrm{~mL})$. The combined organic extracts were dried over $\mathrm{Na}_{2} \mathrm{SO}_{4}$, concentrated in vacuo. The aldehyde $\left(\mathrm{R}_{f} 0.5,3 \%\right.$ EtOAc in petroleum ether), thus obtained, was directly used, after flash chromatography, for the next reaction without any further characterization.

To a stirred solution of anhydrous $\mathrm{CrCl}_{2}(1.9 \mathrm{~g}, 31.98 \mathrm{mmol})$ in THF $(20 \mathrm{~mL})$ under argon atmosphere was added a solution of crude aldehyde and iodoform $(4.19 \mathrm{~g}, 10.66 \mathrm{mmol})$ in THF $(15 \mathrm{~mL})$ at $0{ }^{\circ} \mathrm{C}$ and the reaction mixture was stirred at $0{ }^{\circ} \mathrm{C}$ for $1 \mathrm{~h}$ before being quenched with water $(15 \mathrm{~mL})$. The reaction mixture was extracted with EtOAc $(2 \times 20 \mathrm{~mL})$. The combined organic extracts were washed with water $(10 \mathrm{~mL})$, brine $(10$ $\mathrm{mL}$ ) and dried over $\mathrm{Na}_{2} \mathrm{SO}_{4}$ and concentrated in vacuo. The residue was purified by column chromatography $\left(\mathrm{SiO}_{2}\right.$, hexanes) to afford 20 (1.45 g, 80\% yield) as a colourless viscous liquid. $\mathrm{R}_{f} 0.9$ (5\% EtOAc in hexanes); 
$[\alpha]_{D}^{25}-16.91$ (c 1.2, $\mathrm{CHCl}_{3}$ ). IR (neat): $v_{\max } 2957,2931,2853,1463,1373,1254,1110,954,836,774,671 \mathrm{~cm}^{-1}$; ${ }^{1} \mathrm{H}$ NMR $\left(400 \mathrm{MHz}_{\mathrm{CDCl}}\right.$ ): $\delta 6.47$ (dd, J 14.4, $\left.8.6 \mathrm{~Hz}, 1 \mathrm{H}\right), 5.97$ (dd, J 14.4, $\left.0.9 \mathrm{~Hz}, 1 \mathrm{H}\right), 3.64(\mathrm{dq}, J 6.1,4.8 \mathrm{~Hz}$, $1 \mathrm{H}), 2.16(\mathrm{~m}, 1 \mathrm{H}), 1.07(\mathrm{~d}, J 6.1 \mathrm{~Hz}, 3 \mathrm{H}), 0.89(\mathrm{~d}, J 7.0 \mathrm{~Hz}, 3 \mathrm{H}), 0.88(\mathrm{~s}, 9 \mathrm{H}), 0.03(\mathrm{~s}, 6 \mathrm{H}) ;{ }^{13} \mathrm{C} \mathrm{NMR}(100 \mathrm{MHz}$, $\left.\mathrm{CDCl}_{3}\right): \delta 149.01,74.73,71.19,48.35,25.83,21.23,18.04,15.70,-4.38,-4.81 ; \mathrm{HRMS}(\mathrm{ESI}) \mathrm{m} / z[\mathrm{M}+\mathrm{Na}]^{+}$calcd. for $\mathrm{C}_{12} \mathrm{H}_{25} \mathrm{IOSiNa} 363.0612$, found 363.0616 .

$(2 R, 3 S, E)-5$-lodo-3-methylpent-4-en-2-ol (21). To a stirred solution of compound 20 (1.2 g, $3.52 \mathrm{mmol})$ in dry THF ( $25 \mathrm{~mL})$, TBAF (1M solution in THF $3.87 \mathrm{~mL}, 3.87 \mathrm{mmol}$ ) was added at $0{ }^{\circ} \mathrm{C}$. Reaction mixture was warmed to room temperature and stirred for $12 \mathrm{~h}$. saturated aqueous $\mathrm{NH}_{4} \mathrm{Cl}$ solution $(15 \mathrm{~mL}$ ) was used to quench the reaction mixture, and extracted with EtOAc $(2 \times 20 \mathrm{~mL})$, washed with brine $(15 \mathrm{~mL})$, dried over $\mathrm{Na}_{2} \mathrm{SO}_{4} \mathrm{and}$ concentrated in vacuo. The residue was purified by column chromatography $\left(\mathrm{SiO}_{2}, 8 \% \mathrm{EtOAc} / \mathrm{hexanes}\right)$ to afford 21 ( $0.725 \mathrm{~g}, 91 \%$ yield) as a colourless viscous liquid. $\mathrm{R}_{f} 0.2$ (10\% EtOAc in hexanes); $[\alpha]_{D}{ }^{25}+10.00$ (c $0.25, \mathrm{CHCl}_{3}$ ). IR (neat): $v_{\max } 3403,2956,2857,1253,1095,837,776 \mathrm{~cm}^{-1} ;{ }^{1} \mathrm{H} \mathrm{NMR}\left(500 \mathrm{MHz}, \mathrm{CDCl}_{3}\right): \delta 6.49$ (dd, J 14.4, 8.7 Hz, 1H), 6.12 (dd, J 14.4, $0.6 \mathrm{~Hz}, 1 \mathrm{H}), 3.62$ (p, J $6.1 \mathrm{~Hz}, 1 \mathrm{H}), 2.19(\mathrm{~m}, 1 \mathrm{H}), 1.17(\mathrm{~d}, J 6.3 \mathrm{~Hz}, 3 \mathrm{H}), 1.03$ (d, J $6.9 \mathrm{~Hz}, 3 \mathrm{H}) ;{ }^{13} \mathrm{C} \mathrm{NMR}\left(125 \mathrm{MHz}, \mathrm{CDCl}_{3}\right): \delta 148.09,76.17,70.52,48.32,20.48,15.63 ; \mathrm{HRMS}(\mathrm{ESI}) \mathrm{m} / \mathrm{z}[\mathrm{M}+$ $\mathrm{H}]^{+}$calcd. for $\mathrm{C}_{6} \mathrm{H}_{12} \mathrm{lO} 226.9928$, found 226.9924 .

(2R,3S,E)-5-lodo-3-methylpent-4-en-2-yl 2-(diethoxyphosphoryl)acetate (5). Diethyl phosphonoacetic acid $(1.06 \mathrm{~mL}, 6.63 \mathrm{mmol})$ and DMAP $(0.05 \mathrm{~g}, 0.44 \mathrm{mmol})$ were added sequentially to a stirred solution of 21 (0.500 g, $2.21 \mathrm{mmol}$ ) which was previously azeotroped with benzene, in dry $\mathrm{CH}_{2} \mathrm{Cl}_{2}(10 \mathrm{~mL})$ at $0{ }^{\circ} \mathrm{C}$ under argon atmosphere. After stirring for $10 \mathrm{~min}$ at $0{ }^{\circ} \mathrm{C}, \mathrm{EDCl}(1.27 \mathrm{~g}, 6.63 \mathrm{mmol})$ was added to it and stirred at $\mathrm{rt}$ for another $4 \mathrm{~h}$. Then reaction mixture was quenched with water and extracted with EtOAc $(2 \times 20 \mathrm{~mL})$. The combined organic extracts were washed with brine $(5 \mathrm{~mL})$ and dried over $\mathrm{Na}_{2} \mathrm{SO}_{4}$ and concentrated under vacuo. The residue was purified by column chromatography ( $\mathrm{SiO}_{2}, 30 \%$ EtOAc/hexanes) to afford 5 (0.84 g, $85 \%$ ) as a yellow oil. $\mathrm{R}_{f} 0.2$ (40\% EtOAc /hexanes); $[\alpha]_{D}{ }^{25}+0.8$ (c 1.25, $\mathrm{CHCl}_{3}$ ). IR (neat): $v_{\max } 2938,2861,1739$, 1470, 1395, 1260, 1105, 1055, 1027, 971, 839, 778, $669 \mathrm{~cm}^{-1} ;{ }^{1} \mathrm{H}$ NMR $\left(400 \mathrm{MHz}, \mathrm{CDCl}_{3}\right): \delta 6.46$ (dd, J $14.4,8.6$ $\mathrm{Hz}, 1 \mathrm{H}), 6.09(\mathrm{dd}, J$ 14.4, $0.9 \mathrm{~Hz}, 1 \mathrm{H}), 4.87(\mathrm{~m}, 1 \mathrm{H}), 4.22-4.11(\mathrm{~m}, 4 \mathrm{H}), 2.96(\mathrm{~d}, J 21.6 \mathrm{~Hz}, 2 \mathrm{H}), 2.37(\mathrm{~m}, 1 \mathrm{H}), 1.36-$ $1.31(\mathrm{~m}, 6 \mathrm{H}), 1.17$ (d, J $6.4 \mathrm{~Hz}, 3 \mathrm{H}), 1.03$ (d, J $6.9 \mathrm{~Hz}, 3 \mathrm{H}) ;{ }^{13} \mathrm{C} \mathrm{NMR}\left(100 \mathrm{MHz}, \mathrm{CDCl}_{3}\right): \delta 165.29,146.56,76.45$, 74.04, 62.62, 62.56, 45.17, 35.15, 33.82, 17.20, 16.36, 15.39; HRMS (ESI) $m / z$ [M + Na] $]^{+}$calcd. for $\mathrm{C}_{12} \mathrm{H}_{22} \mathrm{IO}_{5} \mathrm{PNa}$ 427.0141, found 427.0145 .

\section{$(4 S, 5 S, 6 S, 8 R, E)-((2 R, 3 S, E)-5$-lodo-3-methylpent-4-en-2-yl)-9-(tert-butyldimethylsilyloxy)-5-(4-}

methoxybenzyloxy)-4,6,8-trimethylundeca-2,10-dienoate (3). To a stirred solution of compound 5 (0.100 g, $0.22 \mathrm{mmol})$ and $\mathrm{LiCl}(0.02 \mathrm{~g}, 0.44 \mathrm{mmol})$ in $\mathrm{MeCN}(6 \mathrm{~mL})$ at $0{ }^{\circ} \mathrm{C}$, was added $\mathrm{DBU}(0.16 \mathrm{~mL}, 0.22 \mathrm{mmol})$ under argon atmosphere. After stirring at room temperature for $15 \mathrm{~min}$, the mixture was again cooled to $0{ }^{\circ} \mathrm{C}$. Then a solution of aldehyde 4 in $\mathrm{MeCN}(5 \mathrm{~mL}$ ) was added dropwise. After stirring at room temperature for $12 \mathrm{~h}$, the reaction mixture was quenched by addition of water and extracted with EtOAc $(2 \times 20 \mathrm{~mL})$. The combined organic extracts were washed with brine $(5 \mathrm{~mL})$, dried over $\mathrm{Na}_{2} \mathrm{SO}_{4}$, and concentrated under vacuo. The residue was purified by column chromatography $\left(\mathrm{SiO}_{2}, 60-120\right.$ mesh, 6\% EtOAc/hexanes) to afford 3 (0.119 g, $77 \%$ two steps) as a colorless oil. $R_{f} 0.5$ (10\% EtOAc /hexanes); $[\alpha]_{D}{ }^{25}-5.10$ (c 0.75, $\mathrm{CHCl}_{3}$ ). IR (neat): $v_{\max } 2924$, $2855,1713,1649,1513,1458,1248,1179,1071,1036,989,821,583 \mathrm{~cm}^{-1} ;{ }^{1} \mathrm{H} \mathrm{NMR}\left(500 \mathrm{MHz}, \mathrm{CDCl}_{3}\right)$ mixture of two diastereomers at C9 center: $\delta 7.26(\mathrm{~d}, J 7.39 \mathrm{~Hz}, 2 \mathrm{H}), 6.94-6.85(\mathrm{~m}, 3 \mathrm{H}), 6.47$ (ddd, J 15.4, 9.5, $1.0 \mathrm{~Hz}$, $1 \mathrm{H}), 6.09(\mathrm{dt}, J 14.4,1.1 \mathrm{~Hz}, 1 \mathrm{H}), 5.84-5.71(\mathrm{~m}, 2 \mathrm{H}), 5.15-5.04(\mathrm{~m}, 2 \mathrm{H}), 4.91(\mathrm{~m}, 1 \mathrm{H}), 4.55-4.46(\mathrm{~m}, 2 \mathrm{H}), 3.90(\mathrm{~m}$, $1 \mathrm{H}), 3.80(\mathrm{~s}, 3 \mathrm{H}), 3.17(\mathrm{tt}, J \mathrm{~J} .5,2.9 \mathrm{~Hz}, 1 \mathrm{H}), 2.64(\mathrm{~m}, 1 \mathrm{H}), 2.40(\mathrm{~m}, 1 \mathrm{H}), 1.76-1.68(\mathrm{~m}, 2 \mathrm{H}), 1.61(\mathrm{~m}, 1 \mathrm{H}), 1.27$ and 1.25 (two d, $J 7$ and $7.1 \mathrm{~Hz}, 3 \mathrm{H}$ ), 1.19 (d, J $6.3 \mathrm{~Hz}, 3 \mathrm{H}$ ), 1.15 and 1.13 (two d, J 7.0 and $7.4 \mathrm{~Hz}, 3 \mathrm{H}$ ), 1.02 (d, J $6.9,3 \mathrm{H}), 0.97-0.89(\mathrm{~m}, 4 \mathrm{H}), 0.89$ and 0.88 (two s, 9H), $0.84(\mathrm{~d}, J 6.8 \mathrm{~Hz}, 3 \mathrm{H}), 0.02$ and 0.01 (two s, 3H), -0.002 and -0.009 (two s, $3 \mathrm{H}) ;{ }^{13} \mathrm{C} \mathrm{NMR}\left(125 \mathrm{MHz}, \mathrm{CDCl}_{3}\right)$ mixture of two diastereomers at $\mathrm{C} 9$ center: $\delta 165.99$, 
$159.10,152.10,152.02,147.05,140.11,139.07,130.97,130.88,129.19,129.15,120.70,115.17,114.82$, $113.72,84.81,77.79,77.11,76.11,74.69,74.62,72.36,55.26,45.49,40.30,40.08,37.67,37.12,36.97,33.48$, $33.34,25.92,25.88,18.26,18.20,17.36,16.38,15.97,15.57,15.43,15.28,15.04,-4.17,-4.35,-4.82$; HRMS (ESI) $m / z[\mathrm{M}+\mathrm{Na}]^{+}$calcd. for $\mathrm{C}_{34} \mathrm{H}_{55} \mathrm{IO}_{5} \mathrm{SiNa} 721.2753$, found 721.2755.

\section{Experimental procedure for the attempted Heck cyclization reaction (22)}

1. To a stirred solution of $3(0.02 \mathrm{~g}, 0.028 \mathrm{mmol})$ in DMF $(5 \mathrm{~mL})$ were added $\mathrm{Cs}_{2} \mathrm{CO}_{3}(0.016 \mathrm{~g}, 0.05 \mathrm{mmol}), \mathrm{Et}_{3} \mathrm{~N}(0.005 \mathrm{~mL}, 0.033 \mathrm{mmol})$ and $\mathrm{Pd}(\mathrm{OAc})_{2}(0.01 \mathrm{~g}, 0.045 \mathrm{mmol})$ sequentially at $\mathrm{rt}$ under argon atmosphere. After stirring for $48 \mathrm{~h}$ at $\mathrm{rt}$, the reaction mixture was quenched with water and extracted with EtOAc $(2 \times 10 \mathrm{~mL})$. The organic phase was washed with brine $(10 \mathrm{~mL})$, dried over $\mathrm{Na}_{2} \mathrm{SO}_{4}$ and concentrated under vacuo.

2. To a stirred solution of $3(0.02 \mathrm{~g}, 0.028 \mathrm{mmol})$ in $\mathrm{MeCN}(5 \mathrm{~mL})$ was added $\mathrm{Et}_{3} \mathrm{~N}(0.03 \mathrm{~mL}, 0.221 \mathrm{mmol})$, followed by $\mathrm{PdCl}_{2}\left(\mathrm{MeCN}_{2}(0.001 \mathrm{~g}, 0.46 \mathrm{mmol})\right.$ and formic acid $(0.001 \mathrm{~mL}, 0.027 \mathrm{mmol})$ at $\mathrm{rt}$ under argon atmosphere. After stirring for $1 \mathrm{~h}$ at $\mathrm{rt}$, the reaction mixture was quenched by the addition of water $(5 \mathrm{~mL}) \mathrm{and}$ extracted with EtOAc $(2 \times 10 \mathrm{~mL})$. The combined organic layers were washed with brine $(5 \mathrm{~mL})$ and dried over $\mathrm{Na}_{2} \mathrm{SO}_{4}$ and concentrated under vacuo.

3. To a stirred solution of $3(0.02 \mathrm{~g}, 0.028 \mathrm{mmol})$ in DMF $(5 \mathrm{~mL})$ were added $\mathrm{Pd}(\mathrm{OAc})_{2}(0.008 \mathrm{~g}, 0.035 \mathrm{mmol})$ and dry $\mathrm{K}_{2} \mathrm{CO}_{3}(0.032 \mathrm{~g}, 0.233 \mathrm{mmol})$ sequentially at $\mathrm{rt}$ under argon atmosphere. The resulting mixture was stirred at $80^{\circ} \mathrm{C}$ for $2 \mathrm{~h}$ before being quenched by the addition of water $(5 \mathrm{~mL})$ and extracted with EtOAc $(2 \times$ $10 \mathrm{~mL}$ ). The combined organic layers were washed with brine $(5 \mathrm{~mL})$ and dried over $\mathrm{Na}_{2} \mathrm{SO}_{4}$. Evaporation of the solvent under reduced pressure gave crude mass.

4. To a stirred and degassed solution of $3(0.02 \mathrm{~g}, 0.028 \mathrm{mmol})$ in DMF $(5 \mathrm{~mL})$ were added Pd(OAc) 2 (0.006 g, $0.028 \mathrm{mmol})$, dry $\mathrm{K}_{2} \mathrm{CO}_{3}(0.038 \mathrm{~g}, 0.28 \mathrm{mmol})$, and $\mathrm{Bu}_{4} \mathrm{NCl}(0.023 \mathrm{~g}, 0.084 \mathrm{mmol})$ and the mixture was once again degassed. The solution was stirred under argon atmosphere and heated to $60{ }^{\circ} \mathrm{C}$ for $50 \mathrm{~min}$. After cooling to room temperature, diethyl ether $(5 \mathrm{~mL})$ was added, and the solution was washed with water $(5 \mathrm{~mL})$ and extracted with EtOAc $(2 \times 10 \mathrm{~mL})$. The combined organic extracts were washed with brine $(5 \mathrm{~mL})$ and dried over $\mathrm{Na}_{2} \mathrm{SO}_{4}$ and concentrated under vacuo.

\section{Acknowledgements}

Yamini. $V$ is thankful to the CSIR, New Delhi for research fellowship.

\section{Supplementary Material}

${ }^{1} \mathrm{H} \&{ }^{13} \mathrm{C}$ NMR spectra of compound $3,4 a, 5,6,8,10,12-21$.

\section{References}

1. Lee, K. J. Nat. Prod. 2010, 73 (3), 500-516.

https://doi.org/10.1021/np900821e.

2. Wang, X.; Tabudravu, J.; Jaspars, M.; Deng, H. Tetrahedron 2013, 69 (30), 6060-6064.

https://doi.org/10.1016/j.tet.2013.05.094.

3. Ankireddy, S.; Ankireddy, P.; Sabitha, G. Synth. 2015, 47 (18), 2860-2868. 
https://doi.org/10.1055/s-0034-1378739.

4. Reddy, K. M.; Yamini, V.; Singarapu, K. K.; Ghosh, S. Org. Lett. 2014, 16 (10), 2658-2660. https://doi.org/10.1021/ol500875e.

5. Blanchette, M. A.; Choy, W.; Davis, J. T.; Essenfeld, A. P.; Masamune, S.; Roush, W. R.; Sakai, T. Tetrahedron Lett. 1984, 25 (21), 2183-2186. https://doi.org/10.1016/S0040-4039(01)80205-7.

6. Fürstner, A.; Nevado, C.; Waser, M.; Tremblay, M.; Chevrier, C.; Teplý, F.; Aïssa, C.; Moulin, E.; Müller, O. J. Am. Chem. Soc. 2007, 129 (29), 9150-9161.

https://doi.org/10.1021/ja072334v.

7. Yao, G.; Steliou, K. Org. Lett. 2002, 4 (4), 485-488 . https://doi.org/10.1021/ol016943y.

8. Paterson, I.; Wallace, D. J.; Cowden, C. J. Synthesis. 1998, 639-652. https://doi.org/10.1055/s-1998-5929.

9. Shashidhar, J.; Mahender Reddy, K.; Ghosh, S. Tetrahedron Lett. 2011, 52 (24), 3106-3109. https://doi.org/10.1016/j.tetlet.2011.04.008.

10. Myers, A. G.; Yang, B. H.; Chen, H.; Mckinstry, L.; Kopecky, D. J.; Gleason, J. L. J. Am. Chem. Soc. 1997, 7863 (9), 6496-6511. https://doi.org/10.1021/ja970402f.

11. Crimmins, M. T.; King, B. W.; Tabet, E. A.; Chaudhary, K. J. Org. Chem. 2001, 66 (3), 894-902. https://doi.org/10.1021/jo001387r.

12. Reddy, K. M.; Shashidhar, J.; Pottireddygari, G. R.; Ghosh, S. Tetrahedron Lett. 2011, 52 (45), 5987-5991. https://doi.org/10.1016/j.tetlet.2011.08.158.

13. Cowden, Cameron J.; Paterson, I. Organic Reactions. 1997. https://doi.org/10.1002/0471264180.or051.01.

14. Takai, K.; Nitta, K.; Utimoto, K. J. Am. Chem. Soc. 1986, 108 (23), 7408-7410. https://doi.org/10.1021/ja00283a046.

15. Williams, D. R.; Kissel, W. S. J. Am. Chem. Soc. 1998, 120 (43), 11198-11199. https://doi.org/10.1021/ja982572d.

16. Ziegler, F. E.; Chakraborty, U. R.; Weisenfeld, R. B. Tetrahedron 1981, 3 (23), 4035-4040. https://doi.org/10.1016/S0040-4020(01)93278-8.

17. Prasad, K. R.; Pawar, A. B. Org. Lett. 2011, 13 (16), 4252-4255. https://doi.org/10.1021/ol201604c.

18. Jeffery, T. Tetrahedron 1996, 52 (30), 10113-10130. https://doi.org/10.1016/0040-4020(96)00547-9.

19. Dieckmann, M.; Rudolph, S.; Dreisigacker, S.; Menche, D. J. Org. Chem. 2012, 77 (23), 10782-10788. https://doi.org/10.1021/jo302134y. 